\title{
Identification of Early Tomato Fruit Ripening Loci by QTL-seq
}

\author{
E. Ruangrak ${ }^{1,2,3}$, Yongchen $\mathrm{Du}^{2}$, Nang Myint Phyu Sin Htwe ${ }^{3}$, Pimpan Pimorat ${ }^{4} \&$ Jianchang $\mathrm{Gao}^{2}$ \\ ${ }^{1}$ Department of Technology and Industry, Prince of Songkla University, Pattani Campus, Pattani, Thailand \\ ${ }^{2}$ Institute of Vegetables and Flowers, Chinese Academy of Agricultural Sciences, Beijing, China \\ ${ }^{3}$ Urban Agriculture Technology Research Group, Faculty of Science and Technology, Prince of Songkla \\ University, Pattani Campus, Pattani, Thailand \\ ${ }^{4}$ Faculty of Agricultural Technology, Valaya Alongkorn Rajabhat University under the Royal Patronage, Sakaeo \\ Campus, Sakaeo, Thailand \\ Correspondence: Jianchang Gao, Institute of Vegetables and Flowers, Chinese Academy of Agricultural Sciences, \\ Beijing, China. Tel: 81-0736-77-0345. E-mail: gaojianchang@caas.cn
}

Received: September 7, 2018

Accepted: November 1, 2018

Online Published: January 15, 2019

doi:10.5539/jas.v11n2p51

URL: https://doi.org/10.5539/jas.v11n2p51

The research is financed by the National Natural Science Foundation of China (31471874) and the National Key Research and Development Program of China (2016YFD0101703).

\begin{abstract}
QTL-seq has been successfully studied in identifying major QTLs, markers, and candidate genes associated with traits that are important for crop improvement. Tomato earliness is an economically important trait and is a major current research focus recently. This paper reports the identification of tomato early ripening fruit locus facilitated by QTL-seq using a novel next-generation sequencing technology. Two DNA pools of phenotypes of F2 offspring from crosses between the Bone MM (early ripening fruit, P1) and 071-440 (late ripening fruit, P2) cultivars of (Solanum lycopersicum) were bulked for sequencing and alignment analysis. Sequencing results revealed 434 SNP markers on chromosome 11, a candidate QTL at position 52,048,208 bp (named er-fruit) and a candidate gene, Solyc11g071510.1.1. The "er-fruit" as confirmed by the traditional QTL method was related to the early fruit ripening trait in tomato. Additionally, BLAST analysis to known homologies for Solyc11g071510.1.1 gene encodes glycoside hydrolases (GHs). GHs are functionally associated with cell wall degradation, fruit softening and ripening. Thus, GHs may be important in fruit softening, stimulating early fruit ripening in tomato. Our results confirmed that QTL-seq is effective method to identify candidate QTL loci, candidate genes and candidate markers.
\end{abstract}

Keywords: QTL-seq, tomato, early ripening fruit, glycoside hydrolases

\section{Introduction}

Earliness in tomato is one of the factors that needs much concern in recent years due to climatic changes and increased world's population. The ability to bring their products earlier to the market in the season can produce better income for growers (Kevany et al., 2008). Earliness in tomatoes consists of three stages; (1) flowering time, (2) fruit setting time, and (3) fruit ripening time (Powers, 1941). The environmental factors such as temperature and light intensity play a significant role in the expression of any components for early maturity (Kerr, 1955; Adams et al., 2001). It has been reported "Early Cherry' alleles caused reductions in both ripening time and fruit weight by using RAPD marker analysis in $\mathrm{F}_{2}$ population derived from a cross between Lycopersicon esculentum'E6203' (normal ripening) and Lycopersicon esculentum'Early Cherry' (early ripening) (Doganlar et al., 2000).

Early fruit ripening is commercially important and effective trait for tomato (Gur et al., 2010). A QTL (dw1) of the tomato that linked to phenotypic traits, increased yield (quantitative) and earliness (qualitative) have been identified although it caused a decline in fruit firmness (Inai et al., 2006). The tomato is classified as a climacteric fruit that needs phytohormone ethylene to ripen and it also coordinates expression of thousands of genes regulating fruit softening and increasing color development, sugars, acids, and aroma production (Klee \& Giovannoni, 2011). The important fruit ripening phenotypes have been distinguished by rin, nor, $\mathrm{Nr}$ and $\mathrm{Cnr}$ mutants that have been 
provided novel insights into the control of ripening processes (Thompson et al., 1999). In addition, the cell wall modification for softening of the fruit tissues is affected by transcriptional factors nor, rin, and ethylene receptor Never-ripe $(\mathrm{Nr})$ because the transcription level of cell wall degrading enzymes polygalacturonase and pectate-lyase were not observed in rin, nor, and $\mathrm{Nr}$ mutants during tomato fruit ripening (Osorio et al., 2011). Smith and Gross (2000) proposed that a member of glycoside hydrolase family 35 , $\beta$-galactosidase II, may be involved in Gal metabolism during cell wall degradation for softening of tomato fruit, conversion of chloroplasts into chromoplasts, fruit growth, and senescence.

Next-generation sequencing (NGS) technology was proved as a quick accurate and successful method of genome analysis (Takagi et al., 2013a) which involves categorizing molecular markers associated to target genes or genotyping a pair of bulked DNA samples from two dissimilar extreme phenotypes and connecting the markers with QTLs related with chosen traits of research interest (Michelmore et al., 1991; Giovannoni et al., 1991; Mansur et al., 1993; Darvasi \& Soller, 1994). The new approach has been proposed as a means of developing rapid QTL map through the MutMap (Abe et al., 2012), MutMap-Gap (Takagi et al., 2013b), Mutmap+ (Fekih et al., 2013), and QTL-seq (Takagi et al., 2013a) approaches. QTL-seq has developed (Fekih et al., 2013; Takagi et al., 2013a) to replace traditional QTL mapping which is labour-intensive, time-consuming and involves substantial costs associated with the development of DNA markers, genotyping and the generation of a large number of progenies during advanced segregating generations (Takagi et al., 2013a). Moreover, rapid identification of the QTL region (marker and candidate gene) associated with the traits of interest can be performed in the F2 population. The QTL-seq has been employed previously to identify QTLs underlying disease resistance traits in rice (Takagi et al. 2013a), the early flowering trait in cucumber (Lu et al., 2014), seed weight trait in the chickpea (Das et al., 2015), fruit weight, locule number (Illa-Berenguer et al., 2015) and early flowering traits in tomato (Ruangrak et al., 2018). In the present study, we used QTL-seq to identify the QTL for early ripening trait in tomato progenies of cross between naturally selected Bone MM (earliness) and 071-440 (lateness) cultivars.

\section{Method}

\subsection{Plant Materials and Phenotypic Evaluation}

S. lycopersicum cv. Bone MM (Earliness (E); P1 from Russia) and 071-440 (Lateness (L); P2 from China) were used as parents (Figure A1). The genetic backgrounds of Bone MM and 071-440 are extremely different for first fruit ripening characteristics. For the phenotypic evaluation, the first fruit ripening time was visually scored by counting the days from the first flower opening (anthesis) to the first fruit ripening of each plant, developing $90 \%$ red color on fruit surface. The data were used for frequency distribution analysis. F2 progeny showing two extremes (early and late) of first fruit ripening times were isolated and pooled into two bulks (each bulk comprising 30 individuals). The experiment was performed in the tunnel type green house (at day/night average temperatures of $28{ }^{\circ} \mathrm{C} / 15^{\circ} \mathrm{C}$ ) at the Institute of Vegetables and Flowers, Chinese Academy of Agricultural Sciences, Beijing, China $\left(39.96^{\circ} \mathrm{N}, 116.33^{\circ} \mathrm{E}\right)$.

\subsection{QTL-seq Analysis}

Two DNA bulks of extreme early (41-45 days after anthesis) and late (55-59 days after anthesis) ripening times categories were extracted as equal volumes of DNA samples from the F2 progeny by following previously described DNA isolation methods (Abe et al., 2012; Takagi et al., 2013a). The genomic DNA extraction was performed from fresh tomato leaves using the Cetyl Trimethyl Ammonium Bromide (CTAB) method. The whole-genome sequencing was performed using an Illumina Genome IIx sequencer. Pair-end sequencing libraries (read length $100 \mathrm{bp}$ ) with $500 \mathrm{bp}$ insert sizes were prepared for sequencing. The short reads were aligned to the $S$. lycopersicum reference genome sequence (//ftp.ensemblgenomes.org/pub/plants/release-22/ fasta/solanum_lycopersicum/dna/Solanum_lycopersicum.SL2.40.22.dna.toplevel.fa) with BWA software (Li \& Durbin, 2009). SNP-calling was performed using SAM tools software (Li et al., 2009) and then converted into SNP-index as reported (Abe et al., 2012; Fekih et al., 2013; Takagi et al., 2013a). A given result was based on short reads harbouring the SNP being different from the reference sequence (Fekih et al., 2013; Lu et al., 2014). A SNP-index of E- and L-Ripening bulks was subtracted to obtain a $\Delta$ (SNP-index). Fisher's exact test (Fisher, 1922 ) was used to evaluate the statistical significance of the $\Delta$ (SNP-index) values. The detection of functionally annotated putative SNPs and the annotation of the candidate polymorphic marker locus were performed using ANNOVAR software (Wang et al., 2010).

\subsection{Traditional QTL Analysis}

To verify the results of the QTL-seq, conventional QTL analysis using InDel (insertion or deletion) markers was used. Two hundred and three InDel markers were identified from chromosome 11 (Table B1) by aligning E-Ripening Bulk Illumina reads to the reference genome (//ftp.ensemblgenomes.org/pub/plants/release-22/fasta/ 
solanum_lycopersicum/dna/Solanum_lycopersicum.SL2.40.22.dna.toplevel.fa) with BWA/SAMtools software (Li \& Durbin, 2009). The primers of the InDel markers were designed using Primer 3 software (http://simgene.com/Primer3). The DNA of $190 \mathrm{~F} 2$ plants was diluted to approximately $50-100 \mathrm{ng} / \mu \mathrm{l}$ and prepared for InDel marker performance analysis as described in Ruangrak et al. (2018).

\subsection{Protein BLAST Function}

BLAST searches for homologies to known protein functions at the Sol Genomics Network (SGN; http://solgenomics.net/) website were used to infer the function of the candidate gene (Fernandez-Pozo et al., 2015).

\section{Results}

\subsection{Phenotyping and Distribution of Early Fruit Ripening Time in F2 Population}

The early fruit ripening time was scored from the days after anthesis (first flowering) to the ripening of fruit (first fruit) of 1200 individuals of F2 obtained from crossing Bone MM (P1) to 071-440 (P2) cultivars (Figure A1). The frequency distribution of the fruit ripening time is shown in Figure 1. The average number of days after anthesis to ripening of fruit on Bone MM (P1) was approximately 9 days earlier than that in 071-440 (P2), whereas F1 plants ripened 5 days later than P1 and 4 days earlier than P2.

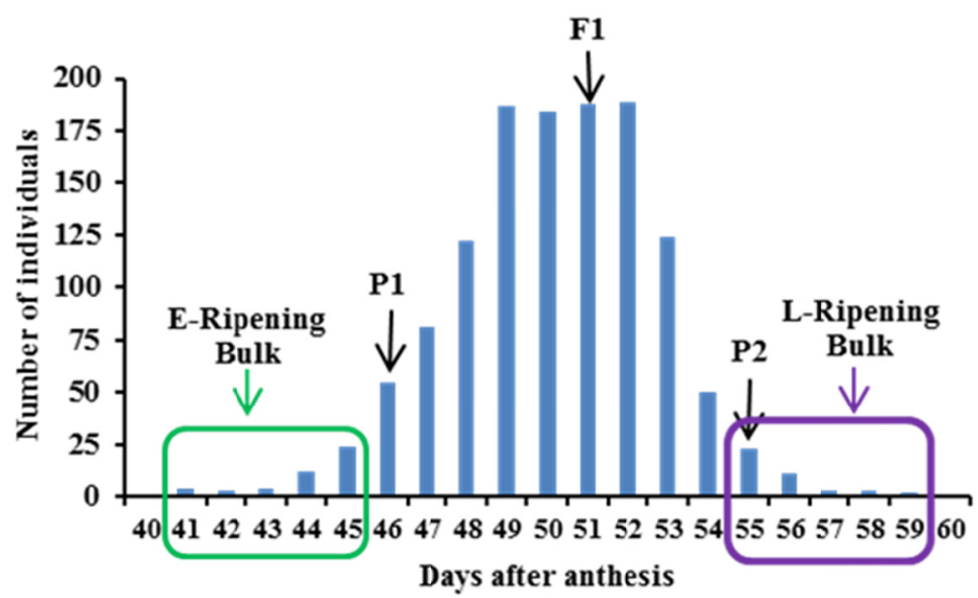

Figure 1. Frequency distribution of ripening time as determined in P1, P2, F1 and F2 populations. The DNAs of early and late ripening plants were bulked to make an early ripening bulk (E-Ripening bulk) and a late ripening bulk (L-Ripening bulk), respectively

\subsection{Sequencing of the Early Fruit Trait}

QTL-seq is based on the cross between two parents that have extreme phenotypic differences followed by selfing of F1 individuals to breed F2 offspring. The DNA samples from 30 F2 individuals showing the phenotypic extremes were bulked in an equal ratio (Figure A1) and subjected to whole genome sequencing with $100 \mathrm{bp}$ paired-end reads for a depth of more than $10 \mathrm{X}$ coverage. To summarize the genotyping and sequencing data assessment, all sample sequence data were considered to be of sufficiently high quality and showed a normal GC distribution. The short reads were aligned to the tomato reference genome sequence using BWA software and the alignment was performed, using SAMTOOLS software for SNP-calling. The results of the alignment suggested that the reference genome size is $781666411 \mathrm{bp}$, and the mapping rate of the aligned samples varied from $93.14 \%$ to $96.3 \%$, for the reference genome (Table B2). The average coverage depth ranged between $16.31 \mathrm{X}$ to 21.09X and the 1X coverage (at least one base coverage) was above $99.56 \%$ (Table B2). Thus, a normal alignment resulted could be considered valuable for the detection of nucleotide change and subsequent analyses.

Furthermore, the ANNOVAR software tool (Wang et al., 2010) was used to locate putative SNPs with respect to predicted genes and to classify them based on function. In the early ripening population, a total of $1,870,498 \mathrm{bp}$ SNPs were detected. The largest number of SNPs $(1,622,942 \mathrm{bp}$, or $86.77 \%)$ were classified in the intergenic region group, while the second largest number of SNPs fell into the intronic group (92,638 bp, or 4.95\%) and the third largest group were located upstream of a gene $(63,263 \mathrm{bp}$, or $3.38 \%)$ followed by downstream of a gene $(52,837 \mathrm{bp}$, or $2.82 \%)$. Furthermore, in terms of SNPs $(<2 \%)$ in coding regions, both non-synonymous $(18,955$ 
bp, or $1.01 \%)$ and synonymous $(13,230 \mathrm{bp}$, or $0.71 \%)$ SNPs were identified. The missense type non-synonymous SNPs again subdivided into SNPs belonging to a stop gain (468 bp, or 0.03\%), a stop loss (168 $\mathrm{bp}$, or $0.01 \%$ ), and splicing group (180 bp, 0.01\%) (Table B3). After screening of each type of SNPs, 1,870,498 polymorphic marker loci were filtered and plotted separately into a part of the SNP-index site and SNP-index graphs from the E- and L-Ripening bulks (Figures S3 and S4, respectively). To identify QTL positions corresponding to the early ripening trait, $\Delta(\mathrm{SNP}$-index) values were compared to identified candidate SNPs (Figure A5). The $\Delta$ (SNP-index) was calculated based on the difference from two SNP-index graphs of E- and L-Ripening bulks, for which putative SNP positions in two different extreme traits should exhibit unequal contribution from two parental genomes (Fekih et al., 2013; Takagi et al., 2013a). Based on the analysis, 434 candidate SNPs were identified and were located on chromosome 11 (Table B4). Annotations of the 434 polymorphic marker loci were generated using ANNOVAR software (Wang et al., 2010).

\subsection{Genomic Region Corresponding to the Early Fruit Ripening Trait}

In this experiment, a genomic region located from 51.0 to $53.0 \mathrm{Mb}$ on chromosome 11 was detected which was associated with the early ripening time phenotype (Figures 2(a)-2(c)). An average $\Delta$ (SNP-index) was computed in a $1 \mathrm{Mb}$ interval using a $1 \mathrm{~Kb}$ sliding window (Figure $\mathrm{A} 2)$. The $\Delta(\mathrm{SNP}$-index ) graphs of the candidate genes were plotted with confidence intervals under the null hypothesis of no QTL $(P<0.05)$. The positions of early fruit ripening time candidate QTL gene were located on chromosome 11. A QTL position was located on the genomic region of 52,048,208 bp in the Solyc11g071350.1.1 gene (Figures 3(a) and 3(c)).

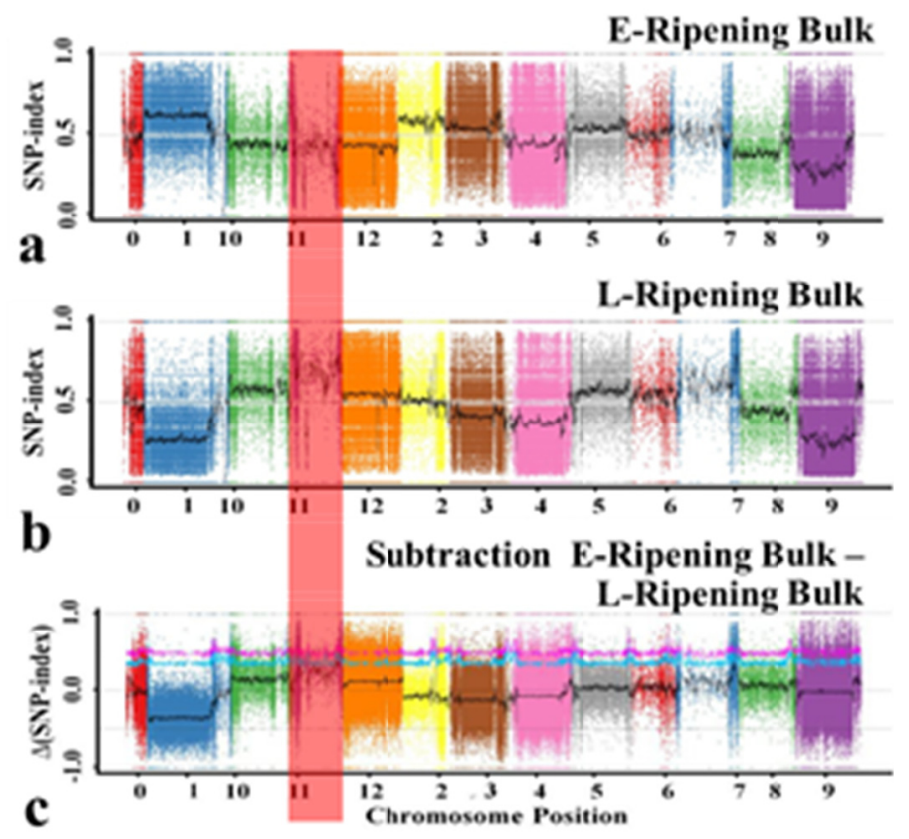

Figure 2. SNP-index graphs of (a) E-Ripening bulk, (b) L-Ripening bulk and (c) Subtraction of E-Ripening bulk to L-Ripening bulk or $\Delta(\mathrm{SNP}$-index) graph from QTL-seq analysis. The X-axis shows the position of the twelve chromosomes and the Y-axis shows the SNP-index (a and b) and $\Delta$ (SNP-index) as given in (c). The $\Delta$ (SNP-index) graph (c) was plotted with statistical confidence intervals under the null hypothesis of no QTL $(\mathrm{P}<0.05)$. The calculation of $\Delta$ (SNP-index), the subtraction of the two SNP-indexes: $\Delta$ (SNP-index) $=$ SNP-index (E-Ripening bulk) - SNP-index (L-Ripening bulk). A 1,000 times permutation test selected 95\% (blue line), 99\% (purple line) confidence level as the screening threshold using Fisher's exact test. The black lines are average values of the SNP-index or $\Delta$ (SNP-index) drawn from the sliding window analysis 


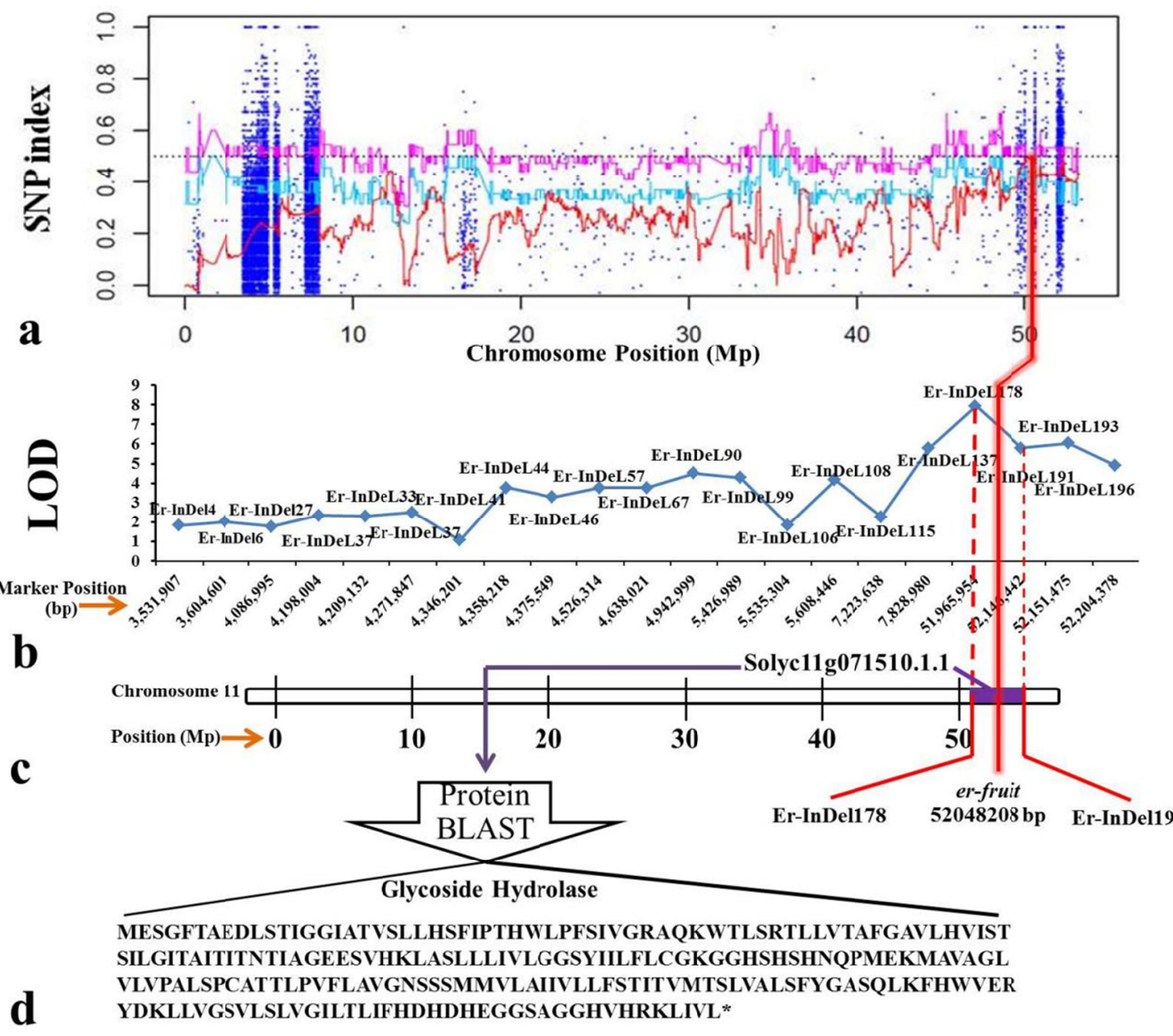

Figure 3. Illustration of the QTL-seq result and confirmation. (a) The SNP-index $\Delta$ (SNP-index) plot of chromosome 11 shows the subtraction of E-Ripening bulk and L-Ripening bulk at ripening time and the red lines are average values of the SNP-index. Additionally, 1,000 times permutation test selected 95\% (blue line) and 99\% (purple line) confidence levels as the screening threshold. (b) The LOD graph of Linkage analysis with 21 Indel markers shows the identification of traditional QTLs on chromosome 11. The Y-axis shows LOD values and the $\mathrm{X}$-axis shows marker positions on chromosome 11. (c) The location of the candidate QTL position and candidate genes on chromosome 11. (d) BLAST protein analysis shows the candidate gene. The red lines are average values of the SNP-index gene

In the detection of QTLs corresponding to early fruit ripening, a total of 1,870,498 SNPs were identified between the Bone MM and 071-440 genomes, and the SNP-index was calculated for each SNP. Graphs showing the relationships between the SNP-index and genomic positions are given in Figures 2(a)-2(c). Highly contrasting patterns of SNP-index graphs were found for E-bulk and L-bulk in the region, suggesting that the early fruit ripening was mainly associated with Bone MM-type genomic segments in the 51.0 to $53.0 \mathrm{Mb}$ region of chromosome 11 (Figures 2(a)-2(c)). On the other hand, late fruit ripening was associated with the 071-440-type genome in the same region, indicating that values of the $\Delta$ (SNP-index) which possibly correspond to QTLs governing the difference between the E- and L-progeny. Statistical confidence intervals of the $\Delta$ (SNP-index) were calculated for all the SNP positions with given read depths under the null hypothesis of no QTLs, and were plotted along with the $\Delta$ (SNP-index) (Figure 2(c)).

\subsection{Traditional QTL Analysis}

The highest LOD (Log of Odds) score $(\mathrm{LOD}=7.94)$ was observed in the interval of InDel markers located at 46.5 and $53.0 \mathrm{Mb}$. This interval was corresponded to the genomic region identified by the QTL-seq method (Figures 2(a)-2(c)). To verify the early ripening QTL which was identified by the QTL-seq method, 190 F2 
plants were used in a traditional QTL analysis. Among 203 InDel markers from chromosome 11, 21 InDel markers were polymorphic between the E- and L-Ripening bulks as shown in Table 1.

Table 1. The information of InDel markers used in the traditional QTL analysis

\begin{tabular}{|c|c|c|c|c|c|}
\hline Marker name & Primer sequences $\left(5^{\prime} \rightarrow 3^{\prime}\right)$ & Position (bp) & LOD Value ${ }^{a}$ & $\mathrm{PVE}^{\mathrm{b}}$ & $\begin{array}{l}\text { Kruskal-Wallis } \\
\text { test }(P)^{\mathrm{c}}\end{array}$ \\
\hline \multirow[t]{2}{*}{ Er-InDel4 } & F: CAGAATTGAGCAACATTCAA & 3531907 & 1.83 & 11.73 & $* *$ \\
\hline & R: AGCTTGGATTCCCTTCTATC & & & & \\
\hline \multirow[t]{2}{*}{ Er-InDel6 } & F: CTAGGGATAGGCATTTTCTG & 3604601 & 2.03 & 11.67 & $* *$ \\
\hline & R: GTACTTAATCAAAGCTCAGCC & & & & \\
\hline \multirow[t]{2}{*}{ Er-InDel27 } & F: TGTTTCTATTCGTGAACCAT & 4086995 & 1.78 & 11.75 & $* *$ \\
\hline & R: TTGTCAAATTCATGATTAAAAG & & & & \\
\hline \multirow[t]{2}{*}{ Er-InDel31 } & F: GGGAAAACCTTAGAATCTTGA & 4198004 & 2.34 & 11.58 & $* *$ \\
\hline & R: TTAGGTAGCGTTTTATGGGA & & & & \\
\hline \multirow[t]{2}{*}{ Er-InDel33 } & F: TTTGCATAGTTTTTGCTCCT & 4209132 & 2.32 & 11.59 & $* * *$ \\
\hline & R: ACCACACCAAATTGACTTTC & & & & \\
\hline \multirow[t]{2}{*}{ Er-InDel37 } & F: ATCCCACGATTAAATCAGC & 4271847 & 2.51 & 11.53 & $* * * *$ \\
\hline & R: TCAATGCTCCCTCACTTATT & & & & \\
\hline \multirow[t]{2}{*}{ Er-InDel41 } & F: AGGAATTATGGGGGATTACA & 4346201 & 1.06 & 10.97 & $* *$ \\
\hline & R: CAAACATCGAATGAACAACA & & & & \\
\hline \multirow[t]{2}{*}{ Er-InDel44 } & F: TTTAGAAGGATGGCCAGATA & 4358218 & 3.76 & 11.17 & $* * * * * *$ \\
\hline & R: TCGAACGTGACCAATAAAAT & & & & \\
\hline \multirow[t]{2}{*}{ Er-InDel46 } & F: CTTCTGGGGTACTCTCTCCT & 4375549 & 3.28 & 11.31 & $* * * * *$ \\
\hline & R: CGAAATTGATATACTATCGGTG & & & & \\
\hline \multirow[t]{2}{*}{ Er-InDel57 } & F: CAAATATACCCGAATCTCCA & 4526314 & 3.77 & 11.17 & $* * * * *$ \\
\hline & R: CTATGAGCGAAACTCCAAGT & & & & \\
\hline \multirow[t]{2}{*}{ Er-InDel67 } & F: AGTCACGAGCTTGAAATTCT & 4638021 & 3.77 & 11.17 & $* * * *$ \\
\hline & R: AACGAGCCATTATTGTCCTA & & & & \\
\hline \multirow[t]{2}{*}{ Er-InDel90 } & F: CATTTTCGGTAAGTTTTTGG & 4942999 & 4.52 & 10.96 & $* * * * * * *$ \\
\hline & R: TGTCGAAAAAGAATTAAACGA & & & & \\
\hline \multirow[t]{2}{*}{ Er-InDel99 } & F: ACCCTCCAAAAATACATGC & 5426989 & 4.28 & 11.03 & $* * * * * * *$ \\
\hline & R: GGATGAAATGGAAAAGACAG & & & & \\
\hline \multirow[t]{2}{*}{ Er-InDel106 } & F: GCATTCATCTAAAGGCAAAC & 5535304 & 1.85 & 11.72 & $* *$ \\
\hline & R: GAACAGATCTCACTTCGGTC & & & & \\
\hline \multirow[t]{2}{*}{ Er-InDel108 } & F: GTAGTGCAACCAAAGACCAC & 5608446 & 4.17 & 11.06 & $* * * * * * *$ \\
\hline & R: TAGCCTAATTGGTCGAGTGT & & & & \\
\hline \multirow[t]{2}{*}{ Er-InDel115 } & F: GTTAGGTTTCAGTTGCCGT & 7223638 & 2.28 & 11.60 & $* * *$ \\
\hline & R: CGAACTTAGTCCATCACCAT & & & & \\
\hline \multirow[t]{2}{*}{ Er-InDel137 } & F: TCAAGTTTCCTTTTGCTTTC & 7828980 & 5.77 & 10.62 & $* * * * * * *$ \\
\hline & R: AGTCCCTATCCACAGATCCT & & & & \\
\hline \multirow[t]{2}{*}{ Er-InDel178 } & F: TGTCGTCACTGACTATTTGG & 51965954 & 7.94 & 10.06 & $* * * * * * *$ \\
\hline & R: CTCCTTGAGGAAAGGACTCT & & & & \\
\hline \multirow[t]{2}{*}{ Er-InDel191 } & F: TCATCTTTCGAGTCGAGATT & 52146442 & 5.80 & 10.61 & $* * * * * * *$ \\
\hline & R: TATCCATTTTGTATAGGGGC & & & & \\
\hline \multirow[t]{2}{*}{ Er-InDel193 } & F: TGAAGGAAACAATGTCACAA & 52151475 & 6.05 & 10.55 & $* * * * * * *$ \\
\hline & R: TACCTGAAAAGAAATCGGAA & & & & \\
\hline \multirow[t]{2}{*}{ Er-InDel196 } & F: TGTTTGTCACAAGTATCTGTTG & 52204378 & 4.90 & 10.86 & $* * * * * * *$ \\
\hline & R: AAATTAGTCGCGTTCCATAC & & & & \\
\hline
\end{tabular}

Note. ${ }^{a}$ LOD value was performed by MQM mapping analysis. ${ }^{b} \mathrm{PVE}$ was the percentage of phenotypic variance calculated by MQM mapping in MapQTL 6.0. Significance: $* P=0.05 ; * * P=0.01 ; * * * P=0.005 ; * * * * P=$ $0.001 ; * * * * P=0.0005 ; * * * * * * P=0.0001 ; * * * * * * P=0.00005$ ( $P$ values from Kruskal-Wallis test are indicated by an asterisk).

These 21 markers were applied to the segregating population for QTL analysis. MQM mapping analysis identified a major QTL for early fruit ripening time delimited by two InDel markers Er-InDel178 and 
Er-InDel191, which were physically located in the region range of $51,965,954$ to $52,146,442 \mathrm{Mb}$ on chromosome 11 (Figure 3(b)). A LOD threshold value of 3.8 was used for declaration of a QTL. The LOD values in this region ranged from 1.06 to 7.94 with the highest peak at marker locus Fl-InDel178 (7.94). This interval was corresponded to the genomic region identified by the QTL-seq method (Figures 2(a)-2(c)). In addition, the candidate gene was aligned to the Solyc11g071350.1.1, encodes glycoside hydrolases (GHs), which was analyzed by BLAST through the Sol Genomics Network (SGN; http://solgenomics.net/) website (Fernandez-Pozo et al., 2015).

\section{Discussion}

QTL-seq is a powerful tool for identifying candidate QTL loci and candidate genes using NGS technology as previously reported (Takagi et al., 2013a; Lu et al., 2014; Das et al., 2015; Illa-Berenguer et al., 2015). This study is aimed to rapidly identify the candidate QTL locus and gene related to the early fruit ripening of the tomato using QTL-seq. Our aim was achieved successfully using naturally selected varieties from Russia (earliness) and China (lateness). The results of phenotyping and the distribution of early fruit ripening time demonstrated that multiple genes control fruit ripening time because the frequency distribution is close to a normal (Gaussian) distribution (Takagi et al., 2013a) (Figure 1). Thus, results suggest that the F2 population can further benefit from the use of QTL-seq analysis. The QTL mapping results confirmed the QTL-seq analysis, supporting the proposition of the QTL located on 52,048,208 bp was a major QTL associated with the early ripening fruit phenotype.

The normal distribution of the F2 population clearly allowed the performance of QTL-seq, which is based on the crossing of two parents that have extreme phenotypic differences followed by selfing of F1 individuals to generate F2 progeny. Takagi et al. (2013a) suggested that an F2 population is much easier to generate than RILs of complex generations. DNA samples of F2 individuals showing extreme phenotypes, i.e. those exhibiting the earliest and latest extreme values of fruit ripening phenotype were bulked in an equal ratio and subjected to whole genome sequencing. In this study, the high base accuracy of Q30 varied from $90.08 \%$ (for L-Ripening bulk) to $92.29 \%$ (P1), with an average of $91.30 \%$ (Table B5) suggested that the sequencing data of all the samples corresponded to low error probabilities and sufficiently high quality. Alignment analysis of the sequencing data showed a candidate QTL located on 52,048,208 bp on the Solyc11g071510.1.1 gene on chromosome 11 and this was confirmed by the result of the traditional QTL method which was consistent with the QTL-seq analysis.

Furthermore, the result of BLAST protein function analysis suggested that this candidate gene encodes glycoside hydrolases (GHs). GHs function as common degradation enzymes with a bond between a carbohydrate, a protein, lipid or another moiety, and are found in many kinds of organisms such as archaea, bacteria, animals and plants (Tyler et al., 2010). Consequently, genes encoding GHs are comparatively abundant in plants where they are involved in processes of starch metabolism, defense, and cell-wall remodeling (Tyler et al., 2010). GH genes play important roles in synthesizing carbohydrate-active enzymes in photosynthesis and in constructing carbohydrate- rich cell walls (Coutinho et al., 2003). Other functions of GHs in plants include pathogen defense, the degradation of starch, and hormone signalling (Minic, 2008). GH genes express to regulate functions in plant cell wall synthesis, renovation, and degradation (Minic \& Jouanin, 2006; Lopez-Casado et al., 2008). In this context, GHs which participate in the degradation of cell wall polysaccharides are also implicated in the governance of plant cell wall loosening, the regulation of growth and development, germination, abscission, cell adhesion and fruit ripening (Fischer \& Bennett, 1991; Minic, 2008). GH genes also play an important role during fruit ripening, with multiple enzymes promoting the disassembly of cell wall polysaccharides or polysaccharide domains and contribute to modifications in cell wall construction. The most characterized and studied cell wall degrading proteins in fruits were reviewed by Owino, Ambuko, and Mathooko (2005). These include GH enzymes such as polygalacturonases (PGs), $\beta$-D-galactosidases, endo-ß-1,4-D-glucanases, and to a lesser extent endo- $\beta$-mannanases, $\beta$-D-xylosidases, $\alpha$-D-galactosidase, and XET (Minic, 2008). $\beta$-galactosidase II plays an important role in degrading galactan and the rise in its activity through tomato ripening suggests a possible role for this enzyme in tomato softening (Smith \& Gross, 2000). During fruit ripening, pectin and some hemicellulosic polysaccharides gradually develop solubility and depolymerize by the release of neutral sugar residues from side chains of matrix polysaccharides (Huber \& O'Donoghue, 1993; Brummell \& Labavitch, 1997).

\section{Concludsion}

In summary of this study, as confirmed by traditional QTL and BLAST protein function analysis, QTL-seq detection found that a GH gene is related to the early fruit ripening trait in the tomato as GH genes are 
functionally associated with cell wall degradation, fruit softening and ripening fruit. Thus, GHs may be important in fruit softening that stimulate early fruit ripening of tomato. These results established that QTL-seq is rapid and effective method to identify candidate QTL loci, candidate genes and candidate markers. In addition, our results are important for plant breeding and crop improvement because early ripening is not only one of the major earliness traits in tomato but also one of the important agronomical traits in crop plants.

\section{Acknowledgements}

The authors would like to thank the members of the Fresh-Tomato research group at the Institute of Vegetables and Flowers, Chinese Academy of Agricultural Sciences and the Key Laboratory of Horticultural Crops Genetic Improvement, Ministry of Agriculture of the People's Republic of China for providing general help and support of this work, the Research and Development Office (RDO), Prince of Songkla University for providing general help in manuscript preparation. This study was funded by the National Natural Science Foundation of China (31471874).

\section{References}

Abe, A., Kosugi, S., Yoshida, K., Natsume, S., Takagi, H., Kanzaki, H., ... Terauchi, R. (2012). Genome sequencing reveals agronomically important loci in rice using MutMap. Nature Biotechnology, 30, 174-178. https://doi.org/10.1038/nbt.2095

Adams, S. R., Cockshull, K. E., \& Cave, C. R. J. (2001). Effect of temperature on the growth and development of tomato fruits. Annals of Botany, 88(5), 869-877. https://doi.org/10.1006/anbo.2001.1524

Brummell, D. A., \& Labavitch, J. M. (1997). Effect of antisense suppression of endopolygalacturonase activity on polyuronide molecular weight in ripening tomato fruit and in fruit homogenates. Plant Physiology, 115, 717-725. https://doi.org/10.1104/pp.115.2.717

Coutinho, P. M., Stam, M., Blanc, E., \& Henrissat, B. (2003). Why are there so many carbohydrate-active enzyme-related genes in plants? Trends in Plant Science, 8, 563-565. https://doi.org/10.1016/j.tplants.2003.10.002

Darvasi, A., \& Soller, M. (1994). Selective DNA pooling for determination of linkage between a molecular marker and a quantitative trait locus. Genetics, 138, 1365-1373.

Das, S., Upadhyaya, H. D., Bajaj, D., Kujur, A., Badoni, S., Laxmi, K. V., ... Parida, S. K. (2015). Deploying QTL-seq for rapid delineation of a potential candidate gene underlying major trait-associated QTL in chickpea. DNA Research, 22, 193-203. https://doi.org/10.1093/dnares/dsv004

Doganlar, S., Tanksley, S. D., \& Mutschler, M. A. (2000). Identification and molecular mapping of loci controlling fruit ripening time in tomato. Theoretical and Applied Genetics, 100(2), 249-255. https://doi.org/ $10.1007 / \mathrm{s} 001220050033$

Fekih, R., Takagi, H., Tamiru, M., Abe, A., Natsume, S., Yaegashi, H., ... Terauchi, R. (2013). MutMap+: Genetic mapping and mutant identification without crossing in rice. PLoS ONE, 8, e68529. https://doi.org/10. 1371/journal.pone.0068529

Fernandez-Pozo, N., Menda, N., Edwards, J. D., Saha, S., Tecle, I. Y., Strickler, S. R., .. Mueller, L. A. (2015). The Sol Genomics Network (SGN) - from genotype to phenotype to breeding. Nucleic Acids Research, 43, D1036-D1041. https://doi.org/10.1093/nar/gku1195

Fischer, R. L., \& Bennett, A. B. (1991). Role of Cell Wall Hydrolases in Fruit Ripening. Annual Review of Plant Physiology and Plant Molecular Biology, 42, 675-703. https://doi.org/10.1146/annurev.pp.42.060191.003331

Fisher, R. A. (1922). On the interpretation of $\chi 2$ from contingency tables, and the calculation of P. Journal of the Royal Statistical Society, 85, 87-94. https://doi.org/10.2307/2340521

Giovannoni, J. J., Wing, R. A., Ganal, M. W., \& Tanksley, S. D. (1991). Isolation of molecular markers from specific chromosomal intervals using DNA pools from existing mapping populations. Nucleic Acids Research, 19, 6553-6558. https://doi.org/10.1093/nar/19.23.6553

Gur, A., Osorio, S., Fridman, E., Fernie, A. R., \& Zamir, D. (2010). hi2-1, a QTL which improves harvest index, earliness and alters metabolite accumulation of processing tomatoes. Theoretical and Applied Genetics, 121, 1587-1599. https://doi.org/10.1007/s00122-010-1412-8

Huber, D. J., \& O’Donoghue, E. M. (1993). Polyuronides in avocado (Persea americana) and tomato (Lycopersicon esculentum) fruits exhibit markedly different patterns of molecular weight downshifts during ripening. Plant Physiology, 102, 473-480. https://doi.org/10.1104/pp.102.2.473 
Illa-Berenguer, E., Van Houten, J., Huang, Z., \& van der Knaap, E. (2015). Rapid and reliable identification of tomato fruit weight and locule number loci by QTL-seq. Theoretical and Applied Genetics, 128, 1329-1342. https://doi: 10.1007/s00122-015-2509-X

Inai, S., Ichihashi, E., Sayama, H., \& Ishimura, E. (2006). Practical use of QTL associated with yield and fruit quality in tomato. Acta Horticulturae, 724, 45-50. https://doi.org/10.17660/ActaHortic.2006.724.4

Kerr, E. A. (1955). Some factors affecting earliness in the tomato. Canadian Journal of Agricultural Science, 35(3), 300-308.

Kevany, B. M., Taylor, M. G., \& Klee, H. J. (2008). Fruit-specific suppression of the ethylene receptor LeETR4 results in early-ripening tomato fruit. Plant Biotechnology Journal, 6, 295-300. https://doi.org/10.1111/ j.1467-7652.2007.00319.x

Klee, H. J., \& Giovannoni, J. J. (2011). Genetics and control of tomato fruit ripening and quality attributes. Annual Review of Genetics, 45, 41-59. https://doi.org/10.1146/annurev-genet-110410-132507

Li, H., \& Durbin, R. (2009). Fast and accurate short read alignment with Burrows-Wheeler transform. Bioinformatics, 25, 1754-1760. https://doi.org/10.1093/bioinformatics/btp324

Li, H., Handsaker, B., Wysoker, A., Fennell, T., Ruan, J., ... Homer, N. (2009). The Sequence Alignment/Map format and SAMtools. Bioinformatics, 25, 2078-2079. https://doi.org/10.1093/bioinformatics/btp352

Lopez-Casado, G., Urbanowicz, B. R., Damasceno, C. M., \& Rose, J. K. (2008). Plant glycosyl hydrolases and biofuels: A natural marriage. Current Opinion in Plant Biology, 11, 329-37. https://doi.org/10.1016/ j.pbi.2008.02.010

Lu, H., Lin, T., Klein, J., Wang, S., Qi, J., Zhou, Q., ... Huang, S. (2014). QTL-seq identifies an early flowering QTL located near Flowering Locus T in cucumber. Theoretical and Applied Genetics, 127, 1491-1499. https://doi.org/10.1007/s00122-014-2313-z

Mansur, L. M., Orf, J., \& Lark, K. G. (1993). Determining the linkage of quantitative trait loci to RFLP markers using extreme phenotypes of recombinant inbreds of soybean (Glycine max L. Merr.). Theoretical and Applied Genetics, 86, 914-918. https://doi.org/10.1007/BF00211041

Michelmore, R. W., Paran, I., \& Kesseli, R. V. (1991). Identification of markers linked to disease-resistance genes by bulked segregant analysis: a rapid method to detect markers in specific genomic regions by using segregating populations. Proceedings of the National Academy of Sciences of the United States of America, 88, 9828-9832. https://doi.org/10.1073/pnas.88.21.9828

Minic, Z. (2008). Physiological roles of plant glycoside hydrolases. Planta, 227, 723-40. https://doi.org/10.1007/ s00425-007-0668-y

Minic, Z., \& Jouanin, L. (2006). Plant glycoside hydrolases involved in cell wall polysaccharide degradation. Plant Physiology and Biochemistry, 44, 435-49. https://doi.org/10.1016/j.plaphy.2006.08.001

Osorio, S., Alba, R., Damasceno, C. M. B., Lopez-Casado, G., Lohse, M., Zanor, M. I., ... Fernie, A. R. (2011). Systems biology of tomato fruit development: combined transcript, protein, and metabolite analysis of tomato transcription factor (nor, rin) and ethylene receptor $(\mathrm{Nr})$ mutants reveals novel regulatory interactions. Plant Physiology, 157, 405-425. https://doi.org/10.1104/pp.111.175463

Owino, W. O., Ambuko, J. L., \& Mathooko, F. M. (2005). Molecular basis of cell wall degradation during fruit ripening and senescence. Stewart Postharvest Review, 1, 1-10. https://doi: 10.2212/spr.2005.3.3

Powers, L. (1941). Inheritance of quantitative characters in crosses involving two species of Lycopersicon. Journal of Agricultural Research, 63, 149-174. https://doi.org/10.3923/pjbs.2006.2770.2776

Ruangrak, E., Su, X., Huang, Z., Wang, X., Guo, Y., Du, Y., \& Gao, J. (2018). Fine mapping of a major QTL controlling early flowering in tomato using QTL-seq. Canadian Journal of Plant Science, 98, $672-682$. https://doi.org/10.1139/cjps-2016-0398

Smith, D. L., \& Gross, K. C. (2000). A Family of at least seven $\beta$-galactosidase genes is expressed during tomato fruit development. Plant Physiology, 123, 1173-1184. https://doi.org/10.1104/pp.123.3.1173

Takagi, H., Abe, A., Yoshida, K., Kosugi, S., Natsume, S., Mitsuoka, C., ... Terauchi, R. (2013a). QTL-seq: rapid mapping of quantitative trait loci in rice by whole genome resequencing of DNA from two bulked populations. The Plant Journal: For Cell and Molecular Biology, 74, 174-183. https://doi.org/10.111 1/tpj.12105 
Takagi, H., Uemura, A., Yaegashi, H., Tamiru, M., Abe, A., Mitsuoka, C., .. Terauchi, R. (2013b). MutMap-Gap: whole-genome resequencing of mutant F2 progeny bulk combined with de novo assembly of gap regions identifies the rice blast resistance gene Pii. The New Phytologist, 200, 276-283. https://doi.org/10.1111/ nph.12369

Thompson, A. J., Tor, M., Barry, C. S., Vrebalov, J., Orfila, C., Jarvis, M. C., ... Seymour, G. B. (1999). Molecular and genetic characterization of a novel pleiotropic tomato-ripening mutant. Plant Physiology, 120, 383-390. https://doi.org/10.1104/pp.120.2.383

Tyler, L., Bragg, J. N., Wu, J., Yang, X., Tuskan, G. A., \& Vogel, J. P. (2010). Annotation and comparative analysis of the glycoside hydrolase genes in Brachypodium distachyon. BMC Genimics, 11, 600. https://doi.org/10.1186/1471-2164-11-600

Wang, K., Li, M., \& Hakonarson, H. (2010). ANNOVAR: functional annotation of genetic variants from high-throughput sequencing data. Nucleic Acids Research, 38, e164. https://doi.org/10.1093/nar/gkq603

\section{Appendix A}

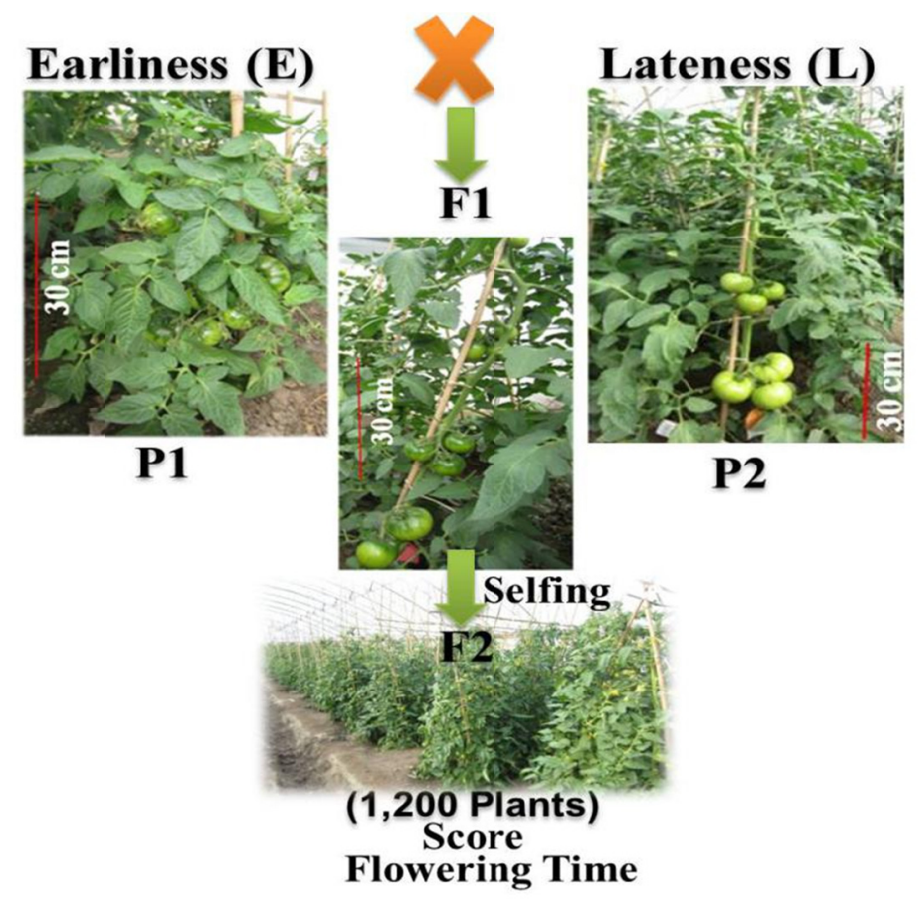

\section{Frequency Distribution}

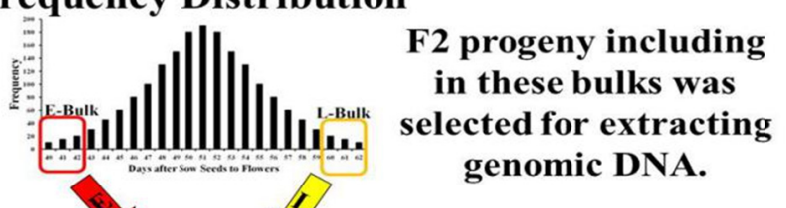

BulkE Bulk L

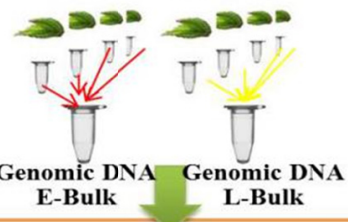

\section{Sequencing and alignment the sequence reads to the reference of the Earliness genome}

Figure A1. Illustration of the QTL-seq method used in this experiment 


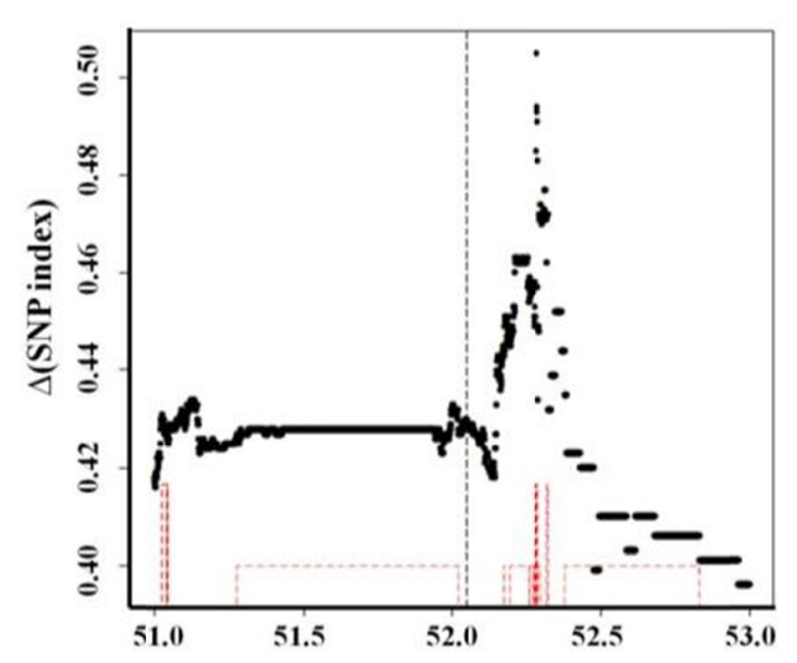

Figure A2. An average of $\Delta$ (SNP-index) was computed in a $1 \mathrm{Mb}$ interval using a $1 \mathrm{~Kb}$ sliding window. The $\triangle$ SNP-index graphs of the candidate genes were plotted with confidence intervals under the null hypothesis of no QTL $(P<0.05)$. The positions of first fruit ripening time candidate gene (Solyc11g071510.1.1: 51M-53M) is located on chromosome 11 


\section{E-Rip SNP index}

Chromosome 1

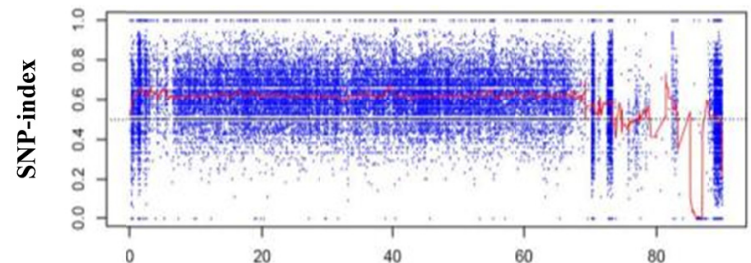

Chromosome 2

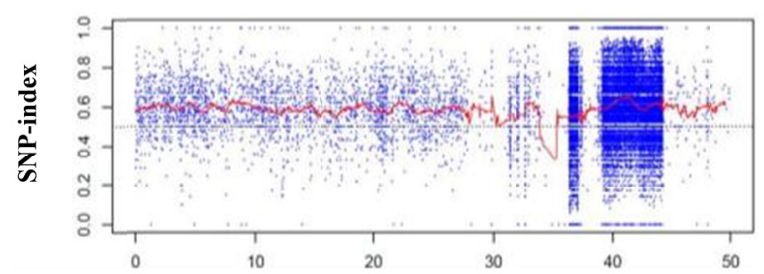

Chromosome 3

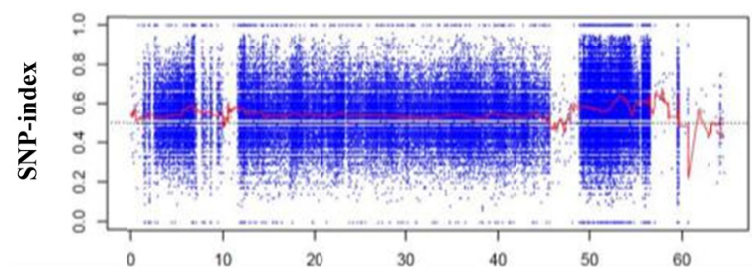

Chromosome 4

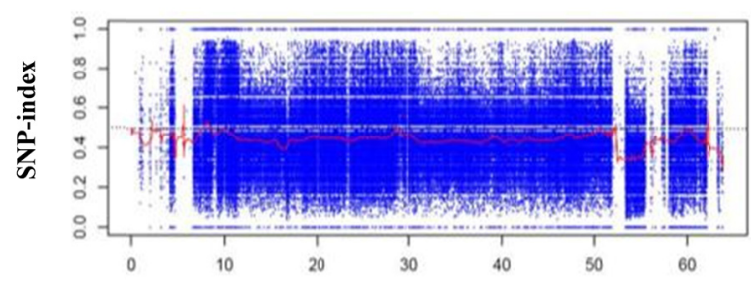

Chromosome 5

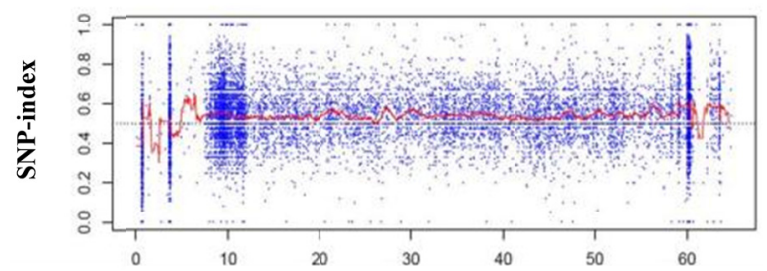

Chromosome 6

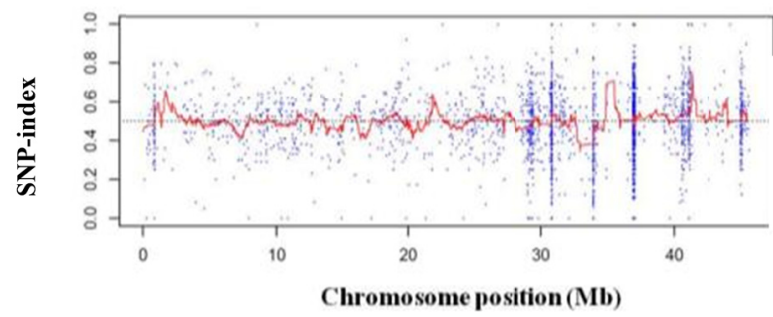

Chromosome 7

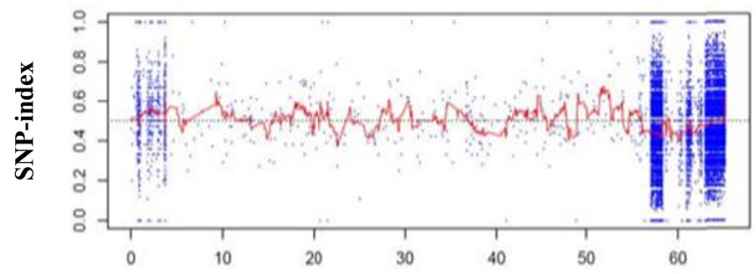

Chromosome 8

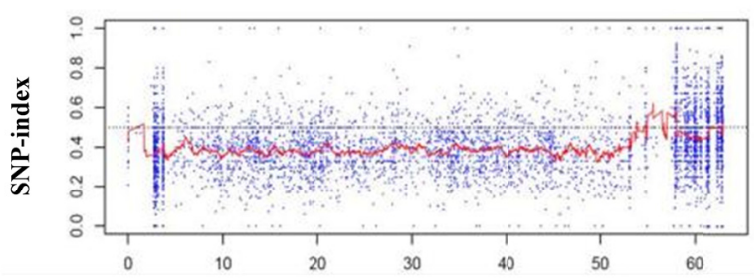

Chromosome 9

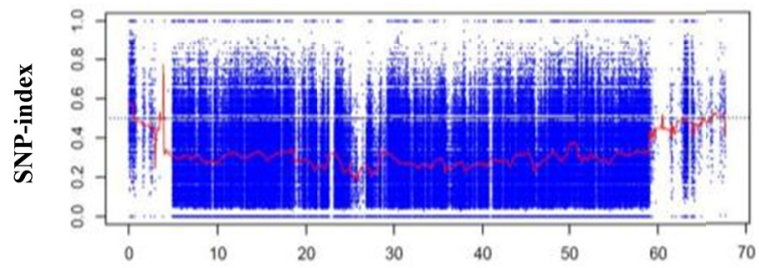

Chromosome 10

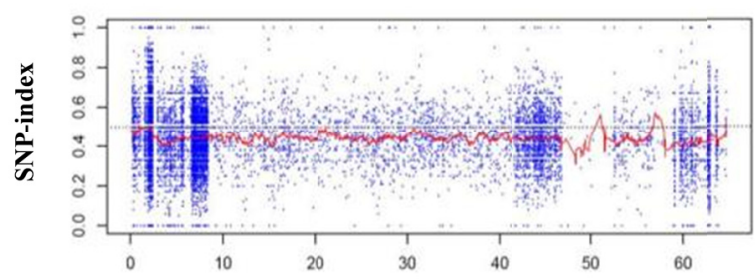

Chromosome 11

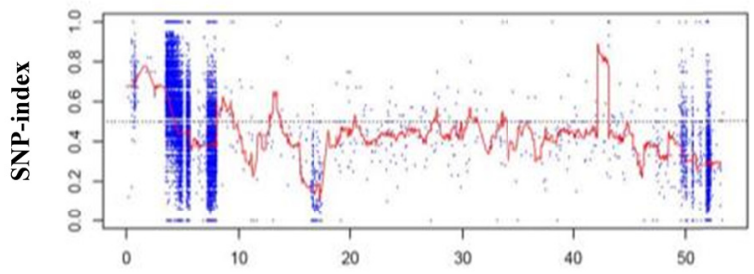

Chromosome 12

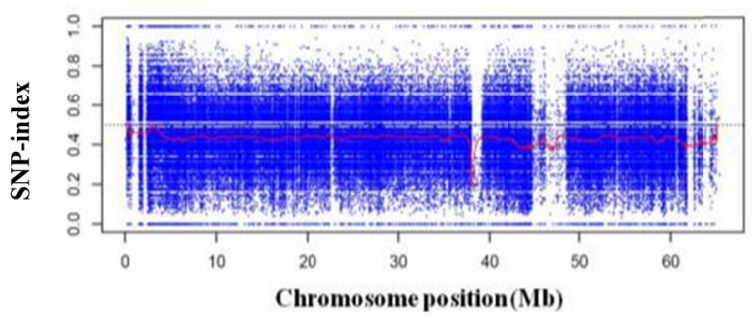

Figure A3. The SNP-index plots of twelve chromosomes which showed bulked DNA of the early fruit ripening (E-Ripening Bulk) at first fruit ripening time. The red lines are average values of the SNP-index or $\Delta$ (SNP-index) drawn by sliding window analysis 


\section{L-Rip SNP index}

Chromosome 1

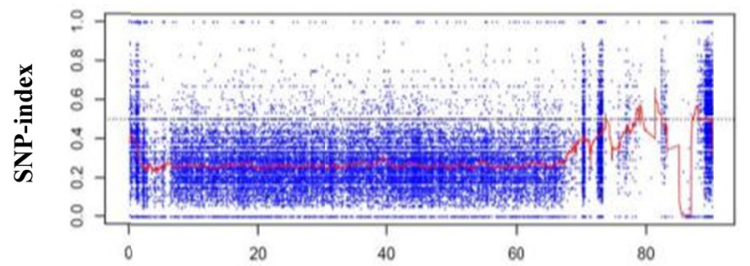

Chromosome 2

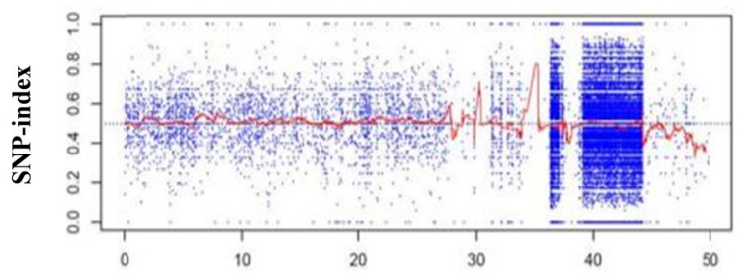

Chromosome 3

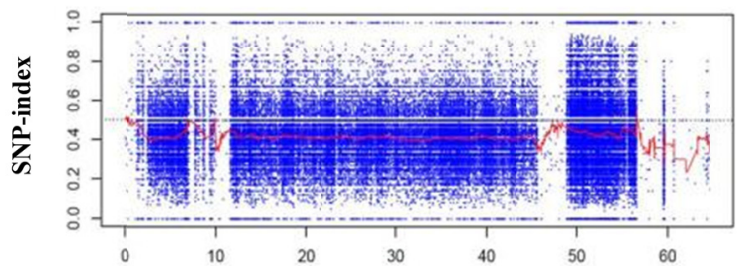

Chromosome 4

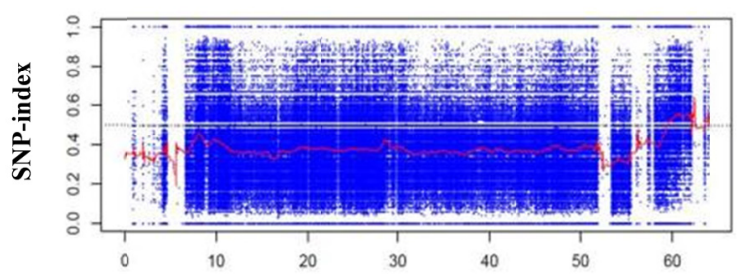

Chromosome 5

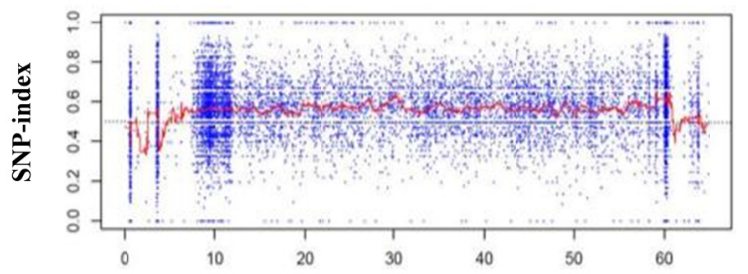

Chromosome 6

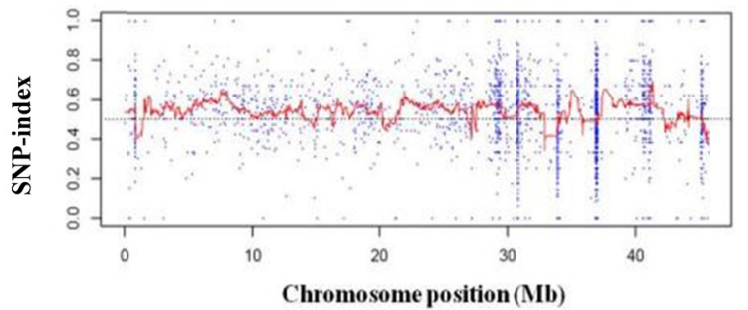

\section{Chromosome 7}

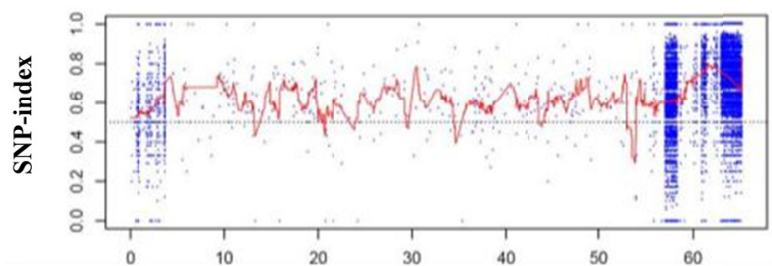

Chromosome 8

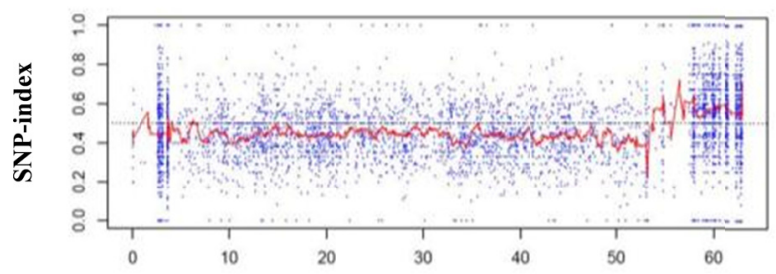

Chromosome 9

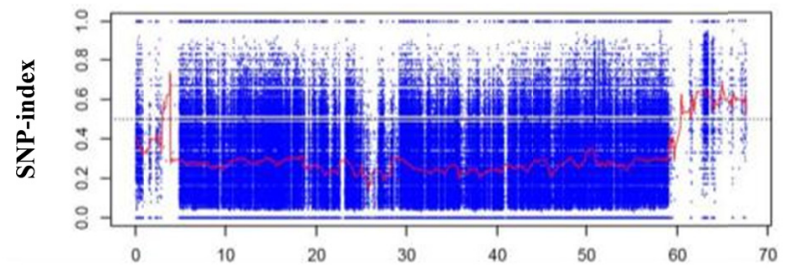

Chromosome 10

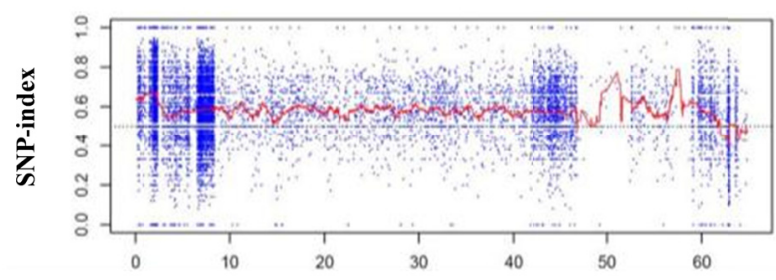

Chromosome 11

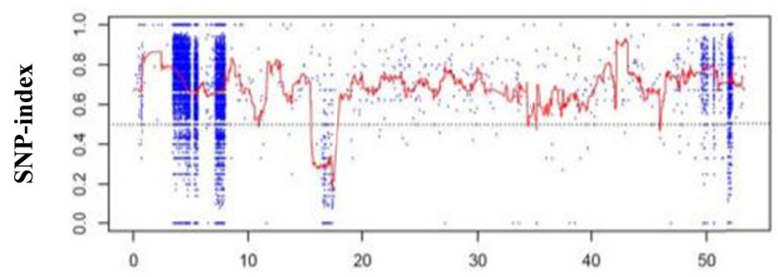

Chromosome 12

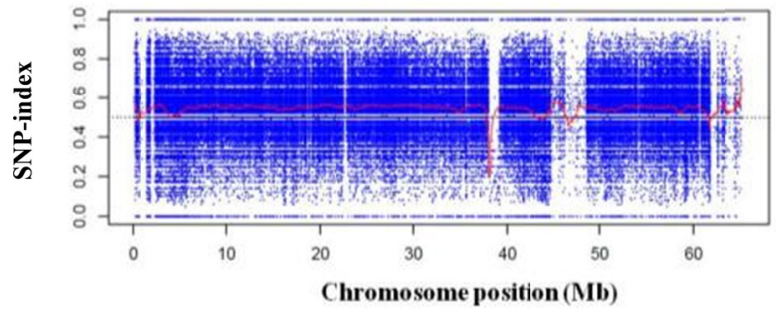

Figure A4. The SNP-index plots of twelve chromosomes which showed bulked DNA of the late fruit ripening (L-Ripening Bulk) at first fruit ripening time. The red lines are average values of SNP-index or $\Delta$ (SNP-index) drawn by sliding window analysis 


\section{Fruit Ripening $\triangle \mathrm{SNP}$ index}

\section{Chromosome 1}

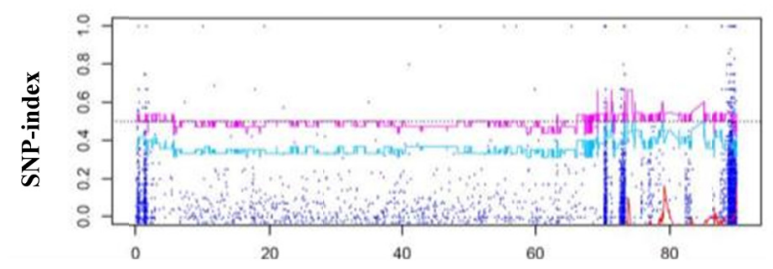

Chromosome 2

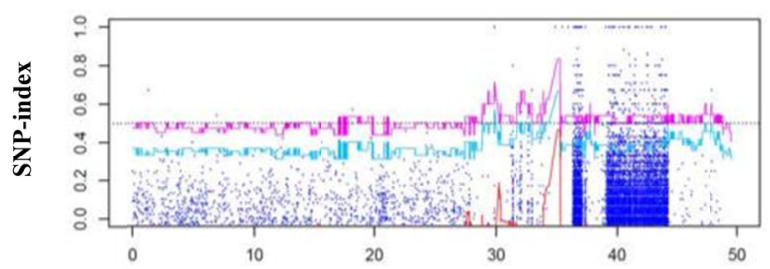

Chromosome 3

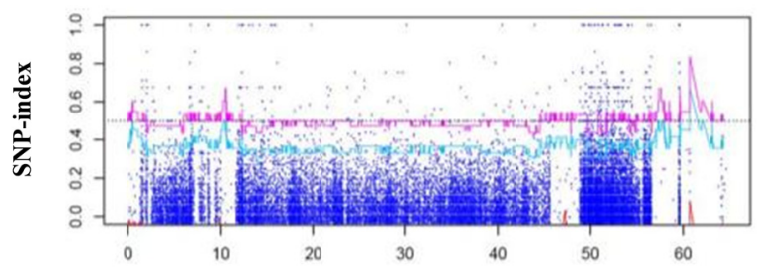

\section{Chromosome 4}

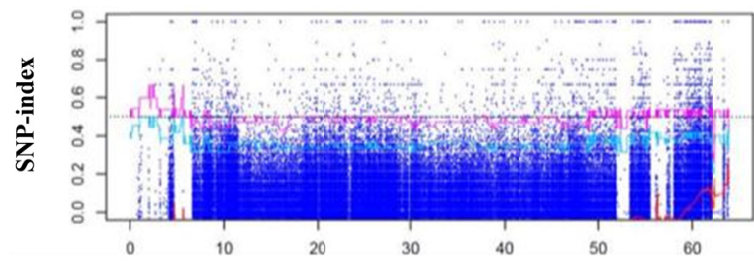

\section{Chromosome 5}

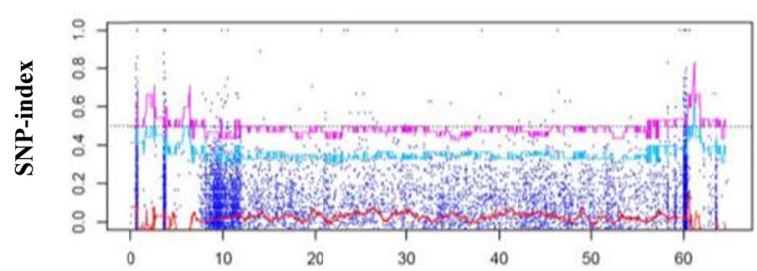

\section{Chromosome 6}

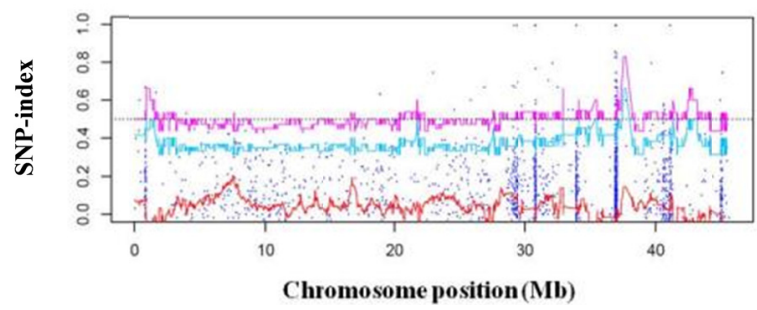

Chromosome 7

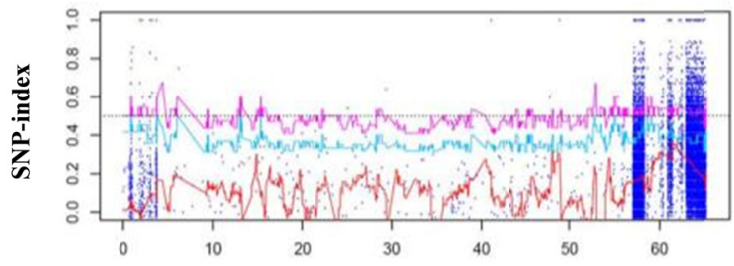

Chromosome 8

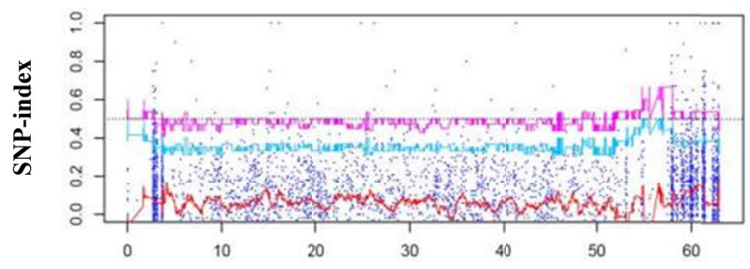

Chromosome 9

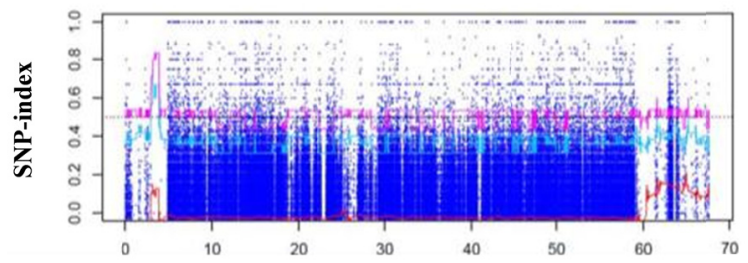

Chromosome 10

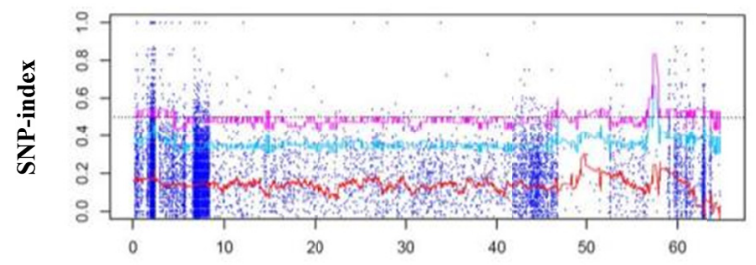

Chromosome 11

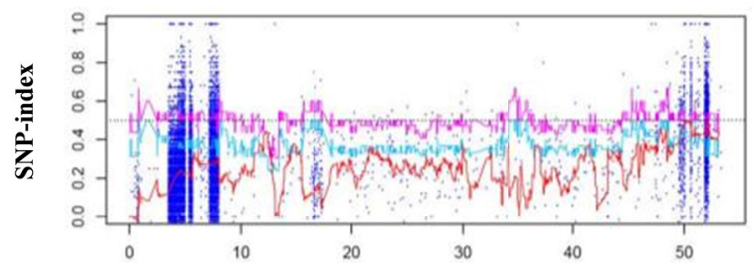

Chromosome 12

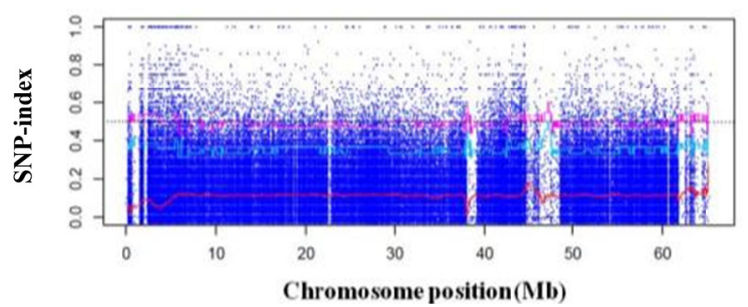

Figure A5. The $\Delta$ (SNP index) plots of twelve chromosomes which showed subtraction of E-Ripening Bulk and L-Ripening Bulk at first fruit ripening time. For the 1000 time permutation test selected 95\% (blue line), 99\% (purple line) confidence level as the screening threshold. The red lines are average values of SNP-index or $\Delta$ (SNP-index) drawn by sliding window analysis 


\section{Appendix B}

Table B1. InDel markers were identified from chromosome 11

\begin{tabular}{|c|c|c|c|c|}
\hline InDel & Position & Forward primer sequences & Reverse primer sequences $\left(5^{\prime} \rightarrow 3^{\prime}\right)$ & size \\
\hline 1 & 2838463 & AATATTCTGGCTTGTCGCTA & CAACCACAGGAGTAACCTTT & 131 \\
\hline 2 & 3125646 & TACTCTTGTATAGTCCATTTCG & ATTTTGCTTCTTTGTTTACG & 114 \\
\hline 3 & 3389559 & GCTTCTATTTAACAATTCCAAA & TGGAATTTTTCTCTTTTACCA & 86 \\
\hline 4 & 3531907 & CAGAATTGAGCAACATTCAA & AGCTTGGATTCCCTTCTATC & 156 \\
\hline 5 & 3597324 & TATTCСССТСАТТССТTТTT & GAATGAAATGTGCAATGGTA & 82 \\
\hline 6 & 3604601 & CTAGGGATAGGCATTTTCTG & GTACTTAATCAAAGCTCAGCC & 158 \\
\hline 7 & 3675820 & TCTTCACTTGCAATCCTCTT & TGGCTTCAGAAATTTGTTTT & 98 \\
\hline 8 & 3686098 & TTGGATCAAAATTTAGTTGG & TGATCGTAATTATTCAAAGAAA & 109 \\
\hline 9 & 3707839 & TCTATTCGTTTGGGACAAAT & AATGATGAACTGAAAGGCAC & 140 \\
\hline 10 & 3712520 & TGATCAAGATTTCAACACAAA & ATGCATTCAATGATCAACAA & 99 \\
\hline 11 & 3715610 & TGAGTGGATAAAAATTCGGT & СТТСТТСТТСАСАСТССАСС & 92 \\
\hline 12 & 3731737 & ATCAGTCGATGGTCTATTGG & CTAAATTTCTGTGGACACCC & 152 \\
\hline 13 & 3756267 & ТСАААААТТСТСТСТСТСАСАА & TCTTTCGGAAATAGAACAAAA & 139 \\
\hline 14 & 3763421 & AAGTTGGACGTGTTGAGATT & GTTTTCATCAAGCGTCAAGT & 95 \\
\hline 15 & 3776827 & АТТTСТTСТТТСССТССАТТ & CGTGACTAATTCAACTCATTTT & 144 \\
\hline 16 & 3792290 & TGATTTAAGCTCTCATTCTTTT & GGAAATAGAAGAATCATCACAA & 136 \\
\hline 17 & 3797724 & TTTATGTTTGTATAAAGCGAGC & TTGAATCGAAATAAAATGTTTG & 81 \\
\hline 18 & 3799535 & TCATCAATAATAATGGGTCAAA & AATAGCAGCACTCACAAACA & 136 \\
\hline 19 & 3962344 & GATTTTCAGTTCTTCATGGG & ACCGAAGCAACCATTAATAC & 135 \\
\hline 20 & 3969654 & TATGTCAAACACTTTGCCTG & AACAATCTTCCAAACTCGAT & 143 \\
\hline 21 & 3988040 & ATCTTCTTGTTGTTTCGACG & TTCATCATCAATCCCTCTTC & 115 \\
\hline 22 & 4005222 & TGTTCAATCAAAAGTCATCG & TGATCCTGATCAGTTACAGGT & 141 \\
\hline 23 & 4011449 & TCGGTCTGCAGAAATAATCT & TTGCATCCTTTTAAATCTTTG & 155 \\
\hline 24 & 4033022 & CTGAATCGATGATGTAGGAA & TGCCACAACTTTTATACGAA & 160 \\
\hline 25 & 4036540 & TGTCTCGACGATGTAAAGAA & TTTCCCAAAAACATATCACC & 120 \\
\hline 26 & 4042055 & CATCTCTTTTGGAATAGACCC & ACAGGTGATTATCTGGTCAAA & 100 \\
\hline 27 & 4086995 & TGTTTCTATTCGTGAACCAT & TTGTCAAATTCATGATTAAAAG & 116 \\
\hline 28 & 4121829 & ATAAAGCCGCATATATTGGA & TATTTTAATGCGCTTCCTTT & 148 \\
\hline 29 & 4125698 & TCCTCAAATTGTGTGAGATTT & CGAGCATTCATACTCGTTTT & 157 \\
\hline 30 & 4187615 & AAAAGAAGGCTTTGATAAGTTC & TGCAATAACAAAGGAAGAAA & 130 \\
\hline 31 & 4198004 & GGGAAAACCTTAGAATCTTGA & TTAGGTAGCGTTTTATGGGA & 130 \\
\hline 32 & 4208813 & GAATGACAACCCTCTTTGAA & TTCTTCAACCATCACAAAAA & 88 \\
\hline 33 & 4209132 & TTTGCATAGTTTTTGCTCCT & ACCACACCAAATTGACTTTC & 134 \\
\hline 34 & 4236711 & СТTТСТTССААААТСААСАТ & TTGAAATTGAGAGAGTACAAAG & 84 \\
\hline 35 & 4237861 & TTGTTGTAGCATTGAACTGAG & TCTTTGGATCATTGATATTTTT & 141 \\
\hline 36 & 4268305 & ATGCATTTTGTAAGTAAATCAA & TTGAGTGTAAAGGGCATAAC & 103 \\
\hline 37 & 4271847 & ATCCCACGATTAAATCAGC & TCAATGCTCССТCACTTATT & 84 \\
\hline 38 & 4305848 & AAAACAGGCCAGCAATAATA & ACAAATTGAAACGAAGATGG & 102 \\
\hline 39 & 4306589 & TCATTTAATATGAATCGCAAA & ATTGGTTAACAGGGTCACTT & 114 \\
\hline 40 & 4316701 & TTCAATTCATCACCTACAACA & AGTTGTGACTAGCTCCTTGC & 136 \\
\hline 41 & 4346201 & AGGAATTATGGGGGATTACA & CAAACATCGAATGAACAACA & 154 \\
\hline 42 & 4347369 & CCCATCAAGGCATAGTATGTA & GTGACATGGTTATTCGACAA & 148 \\
\hline 43 & 4352220 & AACGTCCCTTAAAACGTGTA & GAAATCGAGTCTCTGACGAA & 113 \\
\hline 44 & 4358218 & TTTAGAAGGATGGCCAGATA & TCGAACGTGACCAATAAAAT & 127 \\
\hline 45 & 4363073 & TTAAGGACAAGTAAGCTCCC & CTTGAGGCAAAACAAGAAGT & 121 \\
\hline 46 & 4375549 & СTTCTGGGGTACTCTCTCCT & CGAAATTGATATACTATCGGTG & 144 \\
\hline 47 & 4389174 & GTAAATCCTGAGTTGTTGGG & TTTGTTCTTTCTTAAACTCCG & 86 \\
\hline 48 & 4389947 & ATTGGTGATCATCTTATCCG & TTGAACACAGAACCAGACAA & 113 \\
\hline
\end{tabular}




\begin{tabular}{|c|c|c|c|c|}
\hline 49 & 4416887 & TAGGAGCCTAATCTGGAACA & TATCCAAGTATCTCATGCCC & 132 \\
\hline 50 & 4450426 & GTTAAAAGTACCCCTAAGTGA & AAGCTTATCTTTATTAACTCCA & 140 \\
\hline 51 & 4451523 & TACACCGGCTGTAAAGGTAG & ACCGAAAAGGGATAGAAAAT & 159 \\
\hline 52 & 4456449 & TGGGGTTGTTCTGTTTTTAC & AAACACTGGGAAAATGTCAC & 154 \\
\hline 53 & 4488417 & AAGGAACATGCTTCTTCAAA & TCATTATTGCTCAAAGAGGC & 96 \\
\hline 54 & 4490387 & TTCAATGCCATGTATACCTTT & GTAGACTGTCTTGCAGAGGG & 157 \\
\hline 55 & 4502272 & ACCTAAATGGACCATGAATCT & GCCAATATTGTAATCCCAAA & 103 \\
\hline 56 & 4514878 & GGAAAAATTTGCCTTACATT & TTTTTAAACAAATGTCTCGAAT & 130 \\
\hline 57 & 4526314 & CAAATATACCCGAATCTCCA & CTATGAGCGAAACTCCAAGT & 112 \\
\hline 58 & 4542717 & TTTAATGTCATTCATGTGCAA & TAAATCAACGGAATCTGAGG & 126 \\
\hline 59 & 4549052 & ACACGTGTATCACATTTTCCT & TGGCTAGCTATTTATACGCA & 123 \\
\hline 60 & 4556242 & CAAAAGTGTTGACGTGCTTA & AAGATCACCCTCAACAATGA & 152 \\
\hline 61 & 4556864 & CGTCAAACTATTGGGTCAGT & TGAAATCGTTTCTGGAAAAT & 132 \\
\hline 62 & 4577831 & TTACAACAACTTCGTGCAAC & TTGAGTTTCGGGTATAAGTGA & 155 \\
\hline 63 & 4605203 & AGCGAGACGTACCAAAAATA & AGACTTACGCCTCAATTTCA & 88 \\
\hline 64 & 4618882 & ATAATTGCGCTCAATAGCA & GCCCAAGTCTCTTTCTCTTT & 108 \\
\hline 65 & 4626988 & AAAAGCCCTTAAACAATCAA & TGATTTGTCAAAATGAACAAG & 110 \\
\hline 66 & 4631659 & CGAATGCATCCTTTCTTAAA & CCCATTACCTAGCTTGACAG & 145 \\
\hline 67 & 4638021 & AGTCACGAGCTTGAAATTCT & AACGAGCCATTATTGTCCTA & 123 \\
\hline 68 & 4671136 & AACACTTGATCTACCAAACTCA & TTGGATTATGATTTTACCCTTC & 144 \\
\hline 69 & 4703160 & CACCAAATTCTCTTCACCAT & AGAAATACACAGCAGTTGGG & 111 \\
\hline 70 & 4704795 & TCCTAGCCATTTTGATGAGT & CTTTCATGAGCCTTTTCATC & 144 \\
\hline 71 & 4719917 & TTTATTAATTTAAACGCCGC & TCTAAAAATGAGTGGACCAAA & 133 \\
\hline 72 & 4722366 & AATGTTACATGACACCCCTT & GCTTGTTTTGTTTGTTCTCC & 147 \\
\hline 73 & 4744825 & TATTTTAAACCCTTTTCCGT & GGTCAAACATTAGTCCTTTACA & 132 \\
\hline 74 & 4747534 & CAAAATTCATAGCTAATTTCAA & ATTTAATTTTGTGGACGTGT & 136 \\
\hline 75 & 4748835 & AAAAGGGTTAAAAGGTCAAC & TTTGGAGTAACTCTTCAAGG & 114 \\
\hline 76 & 4749358 & ATGTATGCACCTTGTTTCTT & TTCTTGTATTTTGATTTAAACG & 126 \\
\hline 77 & 4758481 & ATTACAAGCATCATAAGGGG & TTTATGGCATGAGAAGTCAA & 139 \\
\hline 78 & 4765664 & GGAATTGGTAAGAGTCCACA & ATATGTCTCCCACTACCCCT & 145 \\
\hline 79 & 4765856 & TGAGGTTGAAAGAATACCACA & GTTTTTCGACGTGAAATTGT & 112 \\
\hline 80 & 4772480 & TTTTTCTGCTACAATCGAGTC & TGTTCGTGTCAACAAACATT & 132 \\
\hline 81 & 4837346 & TTAATCACGTGCTTGCAATA & CAAACCCTAGCTATTCCATTT & 156 \\
\hline 82 & 4838504 & ССТСТСТССТСССТСТСС & ATTTGTAAATATGGCAAGCG & 152 \\
\hline 83 & 4866926 & TTTTCACCCTTACCATCG & TTTTTATAGTGGTGGGATAGG & 157 \\
\hline 84 & 4867489 & ACACCTAAGGTTGACAATGG & CTTTGGGTCGAACTTTATTG & 109 \\
\hline 85 & 4904804 & AAATTACGGGAAGTAGAAAAAC & TTTGTTTTGTTTAATGGAACC & 108 \\
\hline 86 & 4920067 & AGAAAACTTTGGGAAAAAGG & TACAAGGCTCGTTTTTATGC & 82 \\
\hline 87 & 4932781 & GTGAACGTTATTAAGTGGTTT & TTCATCACTATTTTAАССТTTT & 155 \\
\hline 88 & 4937081 & ATAACCCCCATTCGTCTTT & TCTCTTTTTCTCGCATCAAT & 139 \\
\hline 89 & 4941284 & TGTCAAACACCTTTTCATCA & CGGAATTCGGTAATAGAGTG & 146 \\
\hline 90 & 4942999 & CATTTTCGGTAAGTTTTTGG & TGTCGAAAAAGAATTAAACGA & 136 \\
\hline 91 & 4948461 & AAGTGAAAGTGTGCAACCAT & AGATTCCCTGAAACGTTCTT & 153 \\
\hline 92 & 4983330 & TCCTTCAAGCCCATAAAATA & GATCATAACGACCCTATTGGT & 134 \\
\hline 93 & 4985718 & TTCGTACATTGTGGTTGGTA & AATAATATCCTGGCGATCAA & 157 \\
\hline 94 & 5001460 & AAAGATGTGAAGTCTAGCAAAT & TCGCGATATATATGTGTGTG & 108 \\
\hline 95 & 5309254 & ACCAACCATCCCTTTATTTT & TCCATCACAATACTCAACGA & 130 \\
\hline 96 & 5350273 & AAAGAAAGAAAAGAATCGGG & CTTTTGTTGAGCTTTGAAGG & 158 \\
\hline 97 & 5361713 & AAAGCAAAATAGCGAGAGAA & CAACCCAAAAGCTTAATCAG & 146 \\
\hline 98 & 5424037 & TGTTTGATATGTTATGTTCCCT & CCGAAACGAGACATTTAACTA & 130 \\
\hline 99 & 5426989 & ACССТCСАAАAАTACATGC & GGATGAAATGGAAAAGACAG & 157 \\
\hline 100 & 5428746 & AGGACAAATGAAAATCGAAA & CCAAATAAAATCAGCCCATA & 138 \\
\hline
\end{tabular}




\begin{tabular}{|c|c|c|c|c|}
\hline 101 & 5463728 & CTCAATTTCAATCTTTATGCC & TAGCTAGAGGACCACAAACC & 80 \\
\hline 102 & 5466894 & TGAATGGAGAAAAAGAAAAGA & AAATAGCCTAATTGGCAAAG & 127 \\
\hline 103 & 5480048 & TGATACGTGAATAGGGATTG & AAAAAGAAAGCAAGATAAACG & 83 \\
\hline 104 & 5515271 & GCCCTTGTCTTCTTCACTC & TAGTGAAAACGGGTTGAAGT & 154 \\
\hline 105 & 5516690 & GCTTACGTTTGGACATTGTT & TTTTCAACCTAAGACCTCCA & 139 \\
\hline 106 & 5535304 & GCATTCATCTAAAGGCAAAC & GAACAGATCTCACTTCGGTC & 89 \\
\hline 107 & 5604411 & GGTCACCAAATATTCAAGGA & TTGCTGAAGTTTATCATGGA & 92 \\
\hline 108 & 5608446 & GTAGTGCAACCAAAGACCAC & TAGCCTAATTGGTCGAGTGT & 86 \\
\hline 109 & 6277288 & TCTATCCTTCCTTTTTGTGG & GGGGTGAATGTGACACTAAT & 121 \\
\hline 110 & 6513613 & ACGGAGAAACCAAAAATGTA & AACACGGACGCATATATCTAA & 121 \\
\hline 111 & 6555783 & TTCTTTTTAAAACGGAGAAAGT & TCACCTTCGATTCAATCTTT & 108 \\
\hline 112 & 7179708 & TTTTTCCСТTATCCATTCAA & AGAAACCACCTACGAGATCA & 129 \\
\hline 113 & 7207977 & CACACCCGCTAAAAGTTATT & GCCCAATCAACTATTTTTGT & 107 \\
\hline 114 & 7208496 & GGAGATGAGCGAGATCTGTA & TCTCGCATGTATCCCTATCT & 121 \\
\hline 115 & 7223638 & GTTAGGTTTCAGTTGCCGT & CGAACTTAGTCCATCACCAT & 89 \\
\hline 116 & 7239191 & GGGAAAAATTTGTCTTTCTTG & CTATTTCTGTCCTTTGGCAC & 149 \\
\hline 117 & 7281558 & TATCATGACCGATGTATTCG & TCTTTTGGAATTGACTTCTGA & 140 \\
\hline 118 & 7291112 & TCAAAAGAAAAGAGAAGGTGA & ССТТTТТСССТТТАТССААТ & 155 \\
\hline 119 & 7292091 & ATTTGTGAATTTTTGGCATT & CACTATCCGACCCATTTTTA & 122 \\
\hline 120 & 7313245 & АСССТTTTCTTCTAACGGAA & AAAAATATGTTTGACGAGGATT & 116 \\
\hline 121 & 7322100 & TTCCAAAGAACCGTTACACT & TTAACAACСТTCСАСАТТCC & 141 \\
\hline 122 & 7346925 & ATTTTAGGTAGGTTTTCACGA & GACTTTTAACAGTGAGCGTG & 80 \\
\hline 123 & 7439153 & GCTCGCATGATCTTAATTCT & TCGATAGCTCACTTTGAACA & 108 \\
\hline 124 & 7541872 & CAAGAAAAATGCACAACAAA & СТCСТTTCCATTAGCATCAG & 104 \\
\hline 125 & 7568277 & CCAAAGAACTGTTACACTTTCA & TTAACAACCTTCCACATTCC & 127 \\
\hline 126 & 7574712 & TGGTCTAATGAAGCCTTTGT & ACCGGATAGGGATATTGACT & 136 \\
\hline 127 & 7615512 & ATTTTTGAGAAGTTCGACCA & ATTGAGTCGCTCACGTAAAT & 99 \\
\hline 128 & 7651161 & CATAAGCTCTTCAAATTGCC & TTGGAGAAAACACAACATCA & 142 \\
\hline 129 & 7659778 & CCGTTTTAAAAAGATTGACA & ATGTGGCATGTTTAAGATCA & 143 \\
\hline 130 & 7660678 & TGTCCCTTGCTTTACATTTT & AAGCTGTTTTGAGTATTGCC & 112 \\
\hline 131 & 7679022 & TAATTGAAATGGATGAACCC & СТTCАТСТTCАТСТТССТСG & 153 \\
\hline 132 & 7693896 & TTTTTGTTATGTTTGGCAGA & TTCTCTCTCTCACGCTTTTT & 92 \\
\hline 133 & 7716571 & ATGACTTCCAGCCAAATCTA & TCAAGCAATACAGAGTCGAA & 147 \\
\hline 134 & 7717308 & AAGTTCTTTCCATTCTTCCC & GGCTTTCCAAATTCCTATCT & 84 \\
\hline 135 & 7735695 & TGTGGGAGAGAGGTAAATTG & AATTACGTGGACTGACTTCG & 133 \\
\hline 136 & 7741318 & GAATTGCATCGTTTTTCTTC & AAAATTAAAACCAACGGACA & 113 \\
\hline 137 & 7828980 & TCAAGTTTCCTTTTGCTTTC & AGTCCCTATCCACAGATCCT & 127 \\
\hline 138 & 7847378 & GAGAGACGTAGGAGAGAGG & TTCGTCAGAATATACAATTACA & 145 \\
\hline 139 & 7903813 & TCTACTCGAGGGTTTAAGGA & CCGAACCAGATTACAAATAAA & 142 \\
\hline 140 & 7928572 & TATGGCTGTCACAAACAGAG & AATTTCGATTCGATTTTGAG & 91 \\
\hline 141 & 7946864 & ACCACATTTAAGCACCAAAC & ACGTGAAGTGTGAGTTTTATTG & 133 \\
\hline 142 & 7949256 & GAATTTGGGTTTTGATTTTG & TAAAGTGAAGGGGTGAATTG & 141 \\
\hline 143 & 7995950 & CACTTCATTAACGGGGTAGA & AGTGAGGGAACAATTTCTGA & 109 \\
\hline 144 & 45230496 & CGGTCATCTAAAACACCATT & GAATCTTCGAACAGAGGCTA & 155 \\
\hline 145 & 45258180 & CCCTGAAAAGTTAAGATAGCA & AGCATTATTTTACGGTTTAATG & 97 \\
\hline 146 & 45370701 & ATGGATATATGGATGCCAAC & GATCCTTTTCCAAAGATGTG & 147 \\
\hline 147 & 45709190 & TTTAGGGAAAATGCACAAGT & CGAAAAGGGGTAGAAAATTAC & 141 \\
\hline 148 & 46125680 & GACGTGAACAACGTGACTAA & TACGCCTGACTCCTTATCAT & 131 \\
\hline 149 & 46216965 & AAACTCAAATCCCAAATTCA & CTGTTGTTGATGCTGCTAGA & 100 \\
\hline 150 & 46725937 & TACTTCAATTAAAGCTCGCC & CCCTTTGATCTATGTCGTGT & 105 \\
\hline 151 & 46764362 & ТTTTCTCTCTCTCTTTTCACG & GAATTGGGGTTGATGATAAG & 107 \\
\hline 152 & 46858505 & AAATGCAAGTTTACAAGGGA & AAGACTTGGACTTGGACTTG & 118 \\
\hline
\end{tabular}




\begin{tabular}{|c|c|c|c|c|}
\hline 153 & 47566184 & AAATAATTTTCCGAACTCCC & GGAGAAAACGATTTCACAAA & 96 \\
\hline 154 & 47973834 & TGCAGGAGTAGACTGAAACC & TTTTTGAGTGACTATATGCGAA & 114 \\
\hline 155 & 48262849 & ATACTCGCTTTGCTTCAAAC & GCAATCCAAGCTACAGAAGT & 133 \\
\hline 156 & 48404570 & CGCAACTCCTCTAТCCTAAA & AGAGAATTAAATGGCGTTTG & 109 \\
\hline 157 & 48771672 & TATCAACGTTTGGGATTTTC & CTCAATTTCATTTTGAACCTTT & 126 \\
\hline 158 & 48874074 & GTGAACCAAACTTTAAACGG & GTTTGGTATTTCGTTGTGGT & 150 \\
\hline 159 & 49204628 & CTCTTAACACCACTTTTGCC & ATGAAGAATTTTGGGGTTTT & 90 \\
\hline 160 & 49256128 & ACCTATGGGGTCCTACTGTT & TGTATGCCTGTGATTTGTGT & 120 \\
\hline 161 & 49808261 & TTTTTCGACGTAATTTCAGA & ACTAGACATAACATTGGGTCC & 100 \\
\hline 162 & 49808266 & TTTTTCGACGTAATTTCAGA & ATAACATTGGGTCCAAGAAT & 94 \\
\hline 163 & 49976324 & GCGCATACACCACAAAATTA & CACGTAGGCGGTCCTAATA & 144 \\
\hline 164 & 50000357 & AATGAGTTCAAGGGGGTAAT & GCACATTTTGGGACATACTT & 121 \\
\hline 165 & 50005083 & ATACATTTGTCCAAACCTCC & AAAAAGTATTGGTGTGGTTTT & 112 \\
\hline 166 & 50159967 & TTGATATTGTTGACACCCAA & AAGGATGAAATACCGATGTG & 151 \\
\hline 167 & 50593726 & СССТGATCACTGCTAAACAT & CCACGTACTTACTTGTGGGT & 137 \\
\hline 168 & 50623429 & TCAAATAATTTTGTTCTTGTGA & TCCCAATTTAAATAAAAGCA & 154 \\
\hline 169 & 50806100 & ATTATATGTTTGGTCTCGGG & TCGACTAGTGGTTTGGTTTT & 116 \\
\hline 170 & 51139343 & GCTCTTGGCAAAAGTAAAGA & TCGAAATTTCTGAAAGACGTA & 160 \\
\hline 171 & 51197947 & ССССАТTAАТССТTTTTCA & CTTTAGTTGGTTTTGTTTGTGA & 128 \\
\hline 172 & 51262762 & CGTGAAAAACTTCGAAAAAT & CGAGTTCGAGATTCTGTTTT & 87 \\
\hline 173 & 51272827 & TTGAATTCATCGACAAATAAGA & CATGGAATAGGGATAGTGTCA & 105 \\
\hline 174 & 51370255 & ATGGTTACCAGTCTCTGTCG & AGAAACAGGGGATACTTTGG & 152 \\
\hline 175 & 51922055 & GTAGCCGTAGCACTTGAGAC & AACACGAAAAGAACATCACC & 108 \\
\hline 176 & 51953001 & TTGAAGAAAAAGTTCACAAAAA & СССТTTTTCCAAGAATGTAA & 98 \\
\hline 177 & 51956466 & TGTTTGATTAAATTGGTGAAAT & ATAGCСТCTTTTCAАTCACC & 118 \\
\hline 178 & 51965954 & TGTCGTCACTGACTATTTGG & СTCCTTGAGGAAAGGACTCT & 117 \\
\hline 179 & 51990155 & TCACAAAGGTTTGCTGAATA & TTAACATCATTTTGAGTGCG & 118 \\
\hline 180 & 52006616 & СТСТСАССТСССТССТАТСТ & TAAGAGATAAATTGGGCTGG & 159 \\
\hline 181 & 52034258 & TTGGGTTATTTCAGATTGTTC & GGGTACGGACCCTCTACTAT & 127 \\
\hline 182 & 52045558 & TTGGTTACTGTCCTTTGGTT & AAGCAGTTTGCCATTTATGT & 94 \\
\hline 183 & 52084043 & TTACCССТTCTCTATTGTGC & TTTGGTTAAGCCAACTTTTC & 141 \\
\hline 184 & 52086183 & TAGCATCCATGACTTTGTGA & ACAAGGATTGGTCAATATGC & 134 \\
\hline 185 & 52107486 & TAAAGTCGTCGCTAAAGGTT & GCGACAACTTCATACCTCTT & 123 \\
\hline 186 & 52119815 & TGACACTAAACTAATGCCGA & AAAGGCAAGAGGATTTGATA & 121 \\
\hline 187 & 52120967 & AGGTTGATGGACAATATCTGA & ССАТССАСТАТСССТСТТТА & 155 \\
\hline 188 & 52125009 & AACTTTGCTTCACTTCTTGC & CATACAAACAGGCTTGAACA & 155 \\
\hline 189 & 52139230 & CCCAAATGGACAAATCATTA & TTTGGAAATTTTATCCGTTG & 103 \\
\hline 190 & 52143232 & GGATTACTGACCCTCCTCAT & ATCGAAAGATCTGTGTACGAA & 110 \\
\hline 191 & 52146442 & TCATCTTTCGAGTCGAGATT & TATCCATTTTGTATAGGGGC & 80 \\
\hline 192 & 52150991 & TGAAAGTCTGATGCACAAAG & TTCTCCATAACACAACACGA & 121 \\
\hline 193 & 52151475 & TGAAGGAAACAATGTCACAA & TACCTGAAAAGAAATCGGAA & 122 \\
\hline 194 & 52153089 & TCCTACAGCTATGTTGCTCA & CATTGTTCTGTTTCATGTCG & 100 \\
\hline 195 & 52180545 & GGTCTTCAGGAATCTCAACA & CGAAGTTGTGGTTGTTACAG & 122 \\
\hline 196 & 52204378 & TGTTTGTCACAAGTATCTGTTG & AAATTAGTCGCGTTCCATAC & 141 \\
\hline 197 & 52268761 & TTTTACGTATCACGTTTATTTT & CATTTCACATGCGATAGTTA & 135 \\
\hline 198 & 52270046 & TTGTTTTGTAAAATGATATGGA & TAAAATACACGTGATTCCG & 96 \\
\hline 199 & 52321549 & AATGTCTGGTTCTGATGAGG & GGTTAGAAGCAAGTCCATTG & 134 \\
\hline 200 & 52384121 & ATTTCTCAAATCTGCAAGGA & TTGTTTGCAAATTACTCTCAAC & 122 \\
\hline 201 & 52388226 & TAGGAGGACCCTCTTAAAGC & CACCATCAGGTCTAGTCACC & 94 \\
\hline 202 & 52747446 & TGTACCGTCTTTCTTTTGCT & GAAAAATGTCAATGAAGAGGA & 142 \\
\hline 203 & 52855027 & ATGTTCCCTTCAATCATTTG & TTGTCAACAACCCAAACTAA & 133 \\
\hline
\end{tabular}


Table B2. Sequencing depth and coverage

\begin{tabular}{|c|c|c|c|c|c|c|}
\hline Sample & Total reads ${ }^{1}$ & Mapped reads $^{2}$ & $\begin{array}{l}\text { Mapping rate } \\
(\%)^{3}\end{array}$ & $\begin{array}{l}\text { Average } \\
\text { depth }(X)^{4}\end{array}$ & $\begin{array}{l}\text { Coverageat } \\
\text { least } 1 X^{5}(\%)^{5}\end{array}$ & $\begin{array}{l}\text { Coverageat } \\
\text { least } 4 X^{6}(\%)^{6}\end{array}$ \\
\hline $\mathrm{P}_{1}$ (Bone $\left.\mathrm{MM}\right)$ & 144593794 & 139246400 & 96.30 & 17.68 & 99.19 & 98.27 \\
\hline$P_{2}(440-071)$ & 136509578 & 127146260 & 93.14 & 16.31 & 96.04 & 94.17 \\
\hline E-Ripening Bulk & 175329770 & 166584109 & 95.01 & 21.09 & 99.56 & 97.92 \\
\hline L-Ripening Bulk & 152560340 & 144286570 & 94.58 & 18.19 & 99.23 & 95.82 \\
\hline Average & 152248371 & 144315835 & 94.76 & 18.32 & 98.51 & 96.55 \\
\hline Total & 608993482 & 577263339 & & & & \\
\hline
\end{tabular}

Note. ${ }^{1}$ Effective sequencing data; ${ }^{2}$ Comparison to the reference genome of the read numbers (including single end alignment and double end alignment); ${ }^{3}$ Reference genome reads divided by the effective sequencing data; ${ }^{4}$ The average sequencing depth; ${ }^{5} \mathrm{~A}$ reference genome has at least 1 base covered per site accounting the genome; ${ }^{6} \mathrm{~A}$ reference genome has at least 4 bases covered per site accounting the genome.

Table B3. SNP detection and annotation

\begin{tabular}{|c|c|c|}
\hline \multicolumn{2}{|c|}{ Category } & \multirow{2}{*}{$\begin{array}{l}\text { Number of SNPs } \\
468\end{array}$} \\
\hline \multirow{4}{*}{ Exonic $^{1}$} & Stop gain $^{2}$ & \\
\hline & Stop loss $s^{3}$ & 168 \\
\hline & Synonymous ${ }^{4}$ & 13230 \\
\hline & Non-synonymous ${ }^{5}$ & 18955 \\
\hline \multicolumn{2}{|c|}{ Intronic $^{6}$} & 92638 \\
\hline \multicolumn{2}{|l|}{ Splicing $^{7}$} & 180 \\
\hline \multicolumn{2}{|c|}{ Upstream $^{8}$} & 63263 \\
\hline \multicolumn{2}{|c|}{ Downstream ${ }^{9}$} & 52837 \\
\hline \multicolumn{2}{|c|}{ upstream/downstream ${ }^{10}$} & 4874 \\
\hline \multicolumn{2}{|c|}{ Intergenic $^{11}$} & 1622942 \\
\hline \multicolumn{2}{|c|}{$\operatorname{Ts}^{12}$} & 991440 \\
\hline \multicolumn{2}{|l|}{$\mathbf{T} v^{13}$} & 879058 \\
\hline \multicolumn{2}{|l|}{$\mathbf{T s} / \mathbf{T v} \mathbf{v}^{14}$} & 1127 \\
\hline \multicolumn{2}{|l|}{ Total } & 1870498 \\
\hline
\end{tabular}

Note. ${ }^{1}$ The number of SNPs in an exon region, including stop gain, stop loss, non-synonymous and synonymous; ${ }^{2}$ Introduction of a stop codon; ${ }^{3}$ Loss of a stop codon; ${ }^{4}$ Missense non-synonymous regions; ${ }^{5}$ The number of SNPs presumed to be silent; ${ }^{6}$ The number of SNPs in introns; ${ }^{7}$ Splicing regions are located in the splice site (near the exon/intron boundaries of the $2 \mathrm{bp}$ intron); ${ }^{8} 1 \mathrm{~Kb}$ downstream region; ${ }^{9} 1 \mathrm{~Kb}$ upstream region; ${ }^{10} 1 \mathrm{~Kb}$ upstream/downstream gene; ${ }^{11}$ The number of SNPs in regions between genes; ${ }^{12}$ Transitions (ts) are interchanges between a purine base and another purine $(\mathrm{A} \leftrightarrow \mathrm{G})$ or replacement of a pyrimidine with another pyrimidine $(\mathrm{C} \leftrightarrow \mathrm{T})$; ${ }^{13}$ Transversions (tv) are interchanges between the purine and pyrimidine bases $(T \leftrightarrow A, T \leftrightarrow G, C \leftrightarrow A, C \leftrightarrow G)$; ${ }^{14} \mathrm{ts} / \mathrm{tv}$; Transition/transversion ratio. 
Table B4. The annotations of the candidate polymorphic marker loci

\begin{tabular}{|c|c|c|}
\hline \multicolumn{2}{|c|}{ Category } & \multirow{2}{*}{$\begin{array}{l}\text { Number of SNPs } \\
0\end{array}$} \\
\hline \multirow{4}{*}{ Exonic $^{1}$} & Stop gain $^{2}$ & \\
\hline & Stop loss ${ }^{3}$ & 0 \\
\hline & Synonymous $^{4}$ & 7 \\
\hline & Non-synonymous ${ }^{5}$ & 8 \\
\hline \multicolumn{2}{|c|}{ Intronic ${ }^{6}$} & 41 \\
\hline \multicolumn{2}{|c|}{ Splicing ${ }^{7}$} & 0 \\
\hline \multicolumn{2}{|c|}{ Upstream $^{8}$} & 46 \\
\hline \multicolumn{2}{|c|}{ Downstream9 } & 15 \\
\hline \multicolumn{2}{|c|}{ upstream/downstream ${ }^{10}$} & 2 \\
\hline \multicolumn{2}{|c|}{ Intergenic $^{11}$} & 315 \\
\hline \multicolumn{2}{|c|}{$\operatorname{Ts}^{12}$} & 267 \\
\hline \multicolumn{2}{|l|}{$T v^{13}$} & 167 \\
\hline \multicolumn{2}{|l|}{$\mathrm{Ts} / \mathbf{T v}^{14}$} & 1.598 \\
\hline \multicolumn{2}{|l|}{ Total } & 434 \\
\hline
\end{tabular}

Note. ${ }^{1}$ The number of SNPs in an exon region, including stop gain, stop loss, non-synonymous and synonymous; ${ }^{2}$ Introduction of a stop codon; ${ }^{3}$ Loss of a stop codon; ${ }^{4}$ Missense non-synonymous regions; ${ }^{5}$ The number of SNPs presumed to be silent; ${ }^{6}$ The number of SNPs in introns; ${ }^{7}$ Splicing regions are located in the splice site (near the exon/intron boundaries of the $2 \mathrm{bp}$ intron); ${ }^{8} 1 \mathrm{~Kb}$ downstream region; ${ }^{9} 1 \mathrm{~Kb}$ upstream region; ${ }^{10} 1 \mathrm{~Kb}$ upstream/downstream gene; ${ }^{11}$ The number of SNPs in regions between genes; ${ }^{12}$ Transitions (ts) are interchanges between a purine base and another purine $(\mathrm{A} \leftrightarrow \mathrm{G})$ or replacement of a pyrimidine with another pyrimidine $(\mathrm{C} \leftrightarrow \mathrm{T})$; ${ }^{13}$ Transversions (tv) are interchanges between the purine and pyrimidine bases ( $\left.T \leftrightarrow A, T \leftrightarrow G, C \leftrightarrow A, C \leftrightarrow G\right)$; ${ }^{14}$ ts/tv; Transition/transversion ratio.

Table B5. Sequencing data quality

\begin{tabular}{|c|c|c|c|c|c|c|c|}
\hline Sample & $\begin{array}{l}\text { Raw Base } \\
(\text { bp) }\end{array}$ & $\begin{array}{l}\text { Clean Base } \\
\text { (bp) })^{2}\end{array}$ & $\begin{array}{l}\text { Effective Rate } \\
(\%)^{3}\end{array}$ & $\begin{array}{l}\text { Error Rate } \\
(\%)^{4}\end{array}$ & Q20 (\%) & $\mathrm{Q30}(\%)^{6}$ & $\begin{array}{l}\text { GC Content } \\
(\%)^{7}\end{array}$ \\
\hline $\mathrm{P}_{1}($ Bone $\mathrm{MM})$ & 15048951400 & 14459379400 & 96.08 & 0.03 & 97.33 & 92.29 & 36.17 \\
\hline $\mathrm{P}_{2}(071-440)$ & 14217646400 & 13650957800 & 96.01 & 0.03 & 97.33 & 92.28 & 36.67 \\
\hline E-Ripening Bulk & 18162823000 & 17532977000 & 96.52 & 0.03 & 96.61 & 90.56 & 36.5 \\
\hline L-Ripening Bulk & 15876913600 & 15256034000 & 96.08 & 0.04 & 96.38 & 90.08 & 37.8 \\
\hline Average & 15826583600 & 15224837050 & 96.17 & 0.03 & 96.91 & 91.3 & 36.79 \\
\hline Total & 63306334400 & 60899348200 & & & & & \\
\hline
\end{tabular}

${ }^{1}$ The original data yield of DNA sequences; ${ }^{2}$ The effective data after filtering; ${ }^{3}$ The ratio of raw data after filtering to obtain clean data, error rate and base error rate; ${ }^{4}$ Base error rate; ${ }^{5,6}$ Phred quality scores $\geq$ Q20 and Q30; ${ }^{7}$ The percentage of GC content.

\section{Copyrights}

Copyright for this article is retained by the author(s), with first publication rights granted to the journal.

This is an open-access article distributed under the terms and conditions of the Creative Commons Attribution license (http://creativecommons.org/licenses/by/4.0/). 